\title{
SUPERMAN, a regulator of floral homeotic genes in Arabidopsis
}

\author{
JOHN L. BOWMAN ${ }^{1}$, HAJIME SAKAI ${ }^{1}$, THOMAS JACK ${ }^{1}$, DETLEF WEIGEL ${ }^{1}$, ULRIKE MAYER ${ }^{2}$ and \\ ELLIOT M. MEYEROWITZ ${ }^{1}$ \\ ${ }^{1}$ Division of Biology 156-29, Californa Institute of Technology, Pasadena, California 91125, USA \\ ${ }^{2}$ Institut für Genetik und Mikrobiologie, Universitat München, Maria-Ward-Strasse 1a, 8000 München 19, Germany
}

\begin{abstract}
Summary
We describe a locus, SUPERMAN, mutations in which result in extra stamens developing at the expense of the central carpels in the Arabidopsis thaliana flower. The development of superman flowers, from initial primordium to mature flower, is described by scanning electron microscopy. The development of doubly and triply mutant strains, constructed with superman alleles and previously identified homeotic mutations that cause alterations in floral organ identity, is also described. Essentially additive phenotypes are observed in superman agamous and superman apetala2 double mutants. The epistatic relationships observed between either apetala 3 or pistillata and superman alleles suggest that the SUPERMAN gene product could be a regulator of these floral homeotic genes. To test this, the expression

stamens. In contrast, in superman flowers, APETALA3 expression expands to include most of the cells that would normally constitute the fourth whorl. This ectopic APETALA3 expression is proposed to be one of the causes of the development of the extra stamens in superman flowers. The spatial pattern of $A G A M O U S$ expression remains unaltered in superman flowers as compared to wild-type flowers. Taken together these data indicate that one of the functions of the wild-type SUPERMAN gene product is to negatively regulate APETALA3 in the fourth whorl of the flower. In addition, superman mutants exhibit a loss of determinacy of the floral meristem, an effect that appears to be mediated by the APETALA3 and PISTILLATA gene products.
\end{abstract} patterns of $A G A M O U S$ and $A P E T A L A 3$ were examined in superman flowers. In wild-type flowers, APETALA3 expression is restricted to the second and third whorls where it is required for the specification of petals and

Key words: flower development, Arabidopsis, homeotic genes.

\section{Introduction}

Flowers of Arabidopsis thaliana originate as small outgrowths of cells on the flanks of florally-induced shoot apical meristems. These cells divide and differentiate to produce a precise pattern of four different types of floral organs (sepals, petals, stamens and carpels), with each type being confined to one of four concentric whorls that constitute the wild-type flower. During this process, the cells of the flower primordium learn their relative position and subsequently differentiate appropriately. One approach to understanding how cells realize their fates in developing flowers is to study genes whose wild-type products are necessary for proper pattern formation in Arabidopsis flowers.

Mutations in several genes that disrupt flower pattern in Arabidopsis have been described (Pruitt et al., 1987; Komaki et al., 1988; Bowman et al., 1988; 1989; 1991b; Haughn and Somerville, 1988; Hill and Lord, 1989; Kunst et al., 1989; Meyerowitz et al., 1989; Irish and Sussex, 1990; Yanofsky et al., 1990; Schultz and Haughn, 1991). Recent focus has been on four of these genes ( $A G A M O U S, A P E T A L A 2, A P E T A L A 3$, and PISTILLATA) whose mutant phenotype includes homeotic conversions of floral organs. Based on a series of genetic experiments, it has been proposed that these genes, acting alone and in combination, determine the specification of floral organ identity (Bowman et al., 1991b).

Two of these genes, AGAMOUS (Yanofsky et al., 1990) and $A P E T A L A 3$ (Jack et al., 1992), have been cloned. Both encode proteins with regions that share similarity with the DNA-binding domains of transcriptional factors from humans (SRF; Norman et al., 1988) and yeast (MCM1; Passmore et al., 1988) suggesting that both act as transcription factors. The spatial and temporal expression patterns of both genes, at the level of in situ hybridization to RNA, are consistent with their proposed role in cell fate specification within the developing flower (Drews et al., 1991; Jack et al., 1992). They are expressed in wild-type flowers in those whorls that are disrupted by mutations in the genes, and during the developmental stage when the specification of floral organ identity is thought to take place. That each of the 
genes is initially expressed in a well-defined spatial and temporal pattern early in flower development, suggests that the homeotic genes are responding to earlier-acting genes or signals in the flower primordium. It has been shown that the establishment of the proper initial spatial pattern of $A G A M O U S$ expression is dependent upon the wild-type activity of the floral homeotic gene APETALA2 (Drews et al., 1991), as was suggested by genetic experiments (Bowman et al., 1991b). While it is clear that cross-regulatory interactions between the floral homeotic genes help define their spatial domains of activity, these interactions do not completely explain the localization of homeotic gene activity to specific whorls.

In this paper we describe a gene, SUPERMAN, that acts as a regulator of floral homeotic genes. superman mutants have extra stamens which form at the expense of the central carpels (Bowman and Meyerowitz, 1991; Meyerowitz et al., 1991). Analysis of the development of superman flowers and of double mutant combinations of superman with floral homeotic mutants indicates that the pattern defect in superman flowers is not a simple homeotic conversion of carpels to stamens. The genetic data suggest that one role of the wild-type $S U P E R M A N$ product is to repress the activities of the $A P E T A L A 3$ and PISTILLATA products in the fourth whorl of the developing flower. We show that $A P E$ $T A L A 3$ RNA expression, which is restricted to the second and third whorls in wild-type flowers (Jack et al., 1992), expands into the fourth whorl in superman flowers, supporting the contention that SUPERMAN is a regulator of the initial spatial expression patterns of the floral homeotic gene $A P E T A L A 3$.

\section{Materlals and methods}

\section{Genetic materials}

superman (sup) $-1,-2,-3$, and -4 are recessive and were generated by mutagenesis of seeds with ethylmethane sulfonate (EMS). sup-1 was isolated in the Landsberg ecotype, homozygous for the erecta mutation, while sup $-2,-3$ and -4 were isolated in the Columbia ecotype. sup-1 was isolated in the lab of Gerd Jürgens (University of Munich, Munich, Germany) and has been briefly described in Bowman and Meyerowitz (1991) and Meyerowitz et al. (1991); sup-2 (Schultz and Haughn, 1990) was a gift from Elizabeth Schultz and George Haughn (University of Saskatchewan, Saskatoon, Saskatchewan), its isolation number was flo10; sup-3 was a gift from Russell Malmberg (University of Georgia, Athens); and sup-4 was a gift from John Alvarez and David Smyth (Monash University, Melbourne, Australia). All other strains have been previously described (Bowman et al., 1989; 1991). Wild-type alleles are symbolized in block capitals and italics; mutant alleles in lower case italics. Individual mutant alleles are designated by a number that follows the mutant symbol and a hyphen.

Complementation tests were done with pollen from homozygous sup plants, which was used to fertilize heterozygotes of another allele. Allelism was inferred from a $1: 1$ segregation ratio in the progeny. Allelism of sup-1 with the other alleles was established by crossing all alleles to sup-1. When possible, doubly and triply mutant strains were constructed by manual cross-pollination, using as parents strains homozygous for individual mutations. Since agamous alleles are sterile when homozygous we used heterozygotes as parents. The resulting $F_{1}$ plants were allowed to selfpollinate, and double and triple mutants were selected from the $F_{2}$ plants.

Segregation data for the $F_{2}$ progeny of $F_{1}$ self-crosses was as follows: for sup-1 outcrossed to Landsberg erecta, 90 wild type, 25 sup-1; for sup-1 ap2-1, 76 wild type, 21 ap2-1, 24 sup1,2 sup-1 ap2-1; for sup-1 ap2-2, 62 wild type, 22 ap2-2, 38 sup-1, 7 sup-1 ap 2-2; for sup-1 ag-2, 73 wild type, 10 ag-2 (3 erecta, 7 ERECTA), 13 sup-1, 3 sup-1 ag-2 (all ERECTA). The sup-1 ag-1 ap2-1 plant was identified in the cross pi-1/pi1;ag-1/AG;ap2-1/AP2 $\times$ sup-1/sup-1. The segregation numbers were: 30 wild type, 7 sup-1, 14 pi-1 + sup-1 pi-1 (phenotypes indistinguishable), 4 ag-1, 4 ap 2-1, 1 sup-1 ag-1, 3 ag-1 pi-1 + sup-1 ag-1 pi-1 (phenotypes indistinguishable), 2 ap2-1 pi-1, 3 ag-1 ap2-1, 1 sup-1 ag-1 ap2-1, 2 ag-1 ap2-1 pi-1 + sup-1 ag-1 ap 2-1 pi-1 (phenotypes indistinguishable). sup-1 ag-1 plants were identified in the above cross as well as $p i-1 / p i$ $1 ;$ ag-1/AG $\times$ sup-1/sup-1. The segregation numbers were: 91 wild type, $46 p i-1+$ sup-1 pi-1 (phenotypes indistinguishable), 34 ag-1, 7 sup-1, 9 ag-1 pi-1 + sup-1 ag-1 pi-1 (phenotypes indistinguishable), 4 sup-1 ag-1.

Since no plants in the $F_{2}$ generation from a cross between sup- 1 homozygotes and pi-l homozygotes produced flowers with a phenotype different from sup- 1 and pi- 1 flowers, the double mutant plants were identified by crossing five plants with a phenotype indistinguishable from pi-1 single mutants to sup -1 homozygotes. One cross generated $100 \%$ (8/8) progeny with the sup-1 phenotype, indicating that this particular plant had been homozygous for both pi-1 and sup-1. To prove this conclusively, 8 plants of the genotype sup-1/sup-1;pi-1/PI were allowed to self-fertilize. The progeny resulting from this cross, all of which were homozygous for sup-1, segregated 3:1 (99:32), phenotypically sup-1: phenotypically pi-1, indicating that the double mutant phenotype is the same as that of pi-1. Similarly, to identify sup-1 ap3-1 double mutants, 22 ap3-1. like $\mathrm{F}_{2}$ progeny were obtained from ap3-1/+;sup-1/+ selfed plants. Five of these $F_{2}$ progeny had a distinct phenotype, while 17 had the normal ap 3-1 phenotype. All plants were crossed with sup-1 pollen, and all but one of the distinct ones produced seeds. Of the 17 normal ones, 7 failed to segregate sup, and thus were $S U P / S U P ; 9$ segregated $s u p$ and wild type, and thus were sup-1/SUP. All 4 distinct ones segregated $100 \%$ sup (at least 12 progeny), and were thus inferred to have been sup-1/sup-1.

Seeds were planted on a peat moss/potting soil/sand $(3: 3: 1$, v:v:v) mixture. The plants were grown in incubators under constant cool-white fluorescent light at $25^{\circ} \mathrm{C}$ (unless otherwise stated) and $70 \%$ relative humidity.

\section{Microscopy}

For scanning electron microscopy (SEM), young primary inflorescences were collected, fixed, dissected, coated and photographed as previously described (Bowman et al., 1989, 1991b; Smyth et al., 1990)

\section{In situ hybridization}

Individual flowers or a cluster of flower buds at stages 1-14 of development were dissected and fixed in $3.7 \%$ formaldehyde, $5 \%$ acetic acid, $50 \%$ ethanol. Fixed tissue was dehydrated with ethanol, cleared with xylene, and embedded in paraffin (Paraplast Plus). Embedded tissue was sliced into serial $8 \mu \mathrm{m}$ sections with a Sorvall JB-4 microtome and attached to microscope slides that were coated with poly-L-lysine (Sigma). The in situ hybridizations were carried out as described by Cox and Goldberg (1988). Both $A G$ and $A P 3$ 
contain a putative DNA-binding region termed the MADS box (Schwarz-Sommer et al., 1991) that is present in at least 12 genes of Arabidopsis (Yanofsky et al., 1990; Ma et al., 1991; Jack et al., 1992; Koji Goto, personal communication; Martin Yanofsky and Hong Ma, personal communication). To avoid the possibility of cross-hybridization with the other genes, the MADS box sequences were removed from the plasmids used to make the probes. The probes used in these experiments have been described previously (Drews et al., 1991; Jack et al., 1992). In situ hybridization of $\left[{ }^{3} \mathrm{H}\right]$ poly(U) to inflorescence sections results in a uniform signal over the tissue indicating that the hybridizations shown here reflect relative $A P 3$ and $A G$ RNA concentrations rather than overall poly $(\mathrm{A})^{+}$RNA distributions or probe accessibility. Both antisense and control sense strand probes produced a signal at the outer edge of the sepals in flowers older than stage 7 and, thus, this signal is background.

\section{RFLP mapping}

RFLP mapping was done as described by Chang et al. (1988). The two parents used in the mapping cross were Landsberg erecta sup- 1 and Columbia glabral ( $g l l)$. $F_{1}$ progeny from this cross were allowed to self-fertilize to produce $\mathrm{F}_{2}$ individuals. Linkage of the SUPERMAN locus to $g l l$ on the third chromosome was inferred since no recombinants (sup-1 $\mathrm{gll}$ homozygotes) were observed in $367 \mathrm{~F}_{2}$ progeny. 74 sup $-1 \mathrm{~F}_{2}$ progeny of the cross were further analyzed with respect to genetic linkage to RFLP markers. DNA was prepared from each of the 74 sup- $1 \mathrm{~F}_{2}$ plants and digested with $\mathrm{Bg} / \mathrm{II}$ and EcoRI and probed with RFLP markers generated by Chang et al. (1988) and others. Linkage observed with KG-23 (Koji Goto, unpublished), $\lambda$ bat 105 and pCITf7P was 6 (6 recombinants/94 meioses), $6(5 / 80)$, and $9(11 / 122)$ centimorgans (cM) respectively. KG-23 exhibits linkage to $\lambda$ bat 433 of about $1 \mathrm{cM}$ (Koji Goto and E. M. M. unpublished) and pCITf7P distal to $\lambda$ bat105 of about $3 \mathrm{cM}$. As the recombinant progeny pattern of $\lambda$ bat 105 was the same as that of pCITf7P, but not of KG-23, the SUPERMAN locus maps distal to $\lambda$ bat 433 and proximal to $\lambda$ bat 105 on the third chromosome. The linkage analysis was performed using MAPMAKER (Lander et al., 1987).

\section{Results}

\section{Wild type}

Wild-type Arabidopsis thaliana flowers (Fig. 1A-D) contain four concentric regions (whorls), each occupied by a different organ type (Smyth et al., 1990). The first (outermost) whorl of the wild-type flower contains four sepals, two medial and two lateral (with respect to the stem of the inflorescence). The second whorl contains four petals, which are in alternate positions with the sepals. The third whorl includes six stamens, four long medial ones, and two short lateral ones. The fourth whorl is occupied by the gynoecium, which consists of a two-chambered ovary topped with a short style, and capped with stigmatic papillae. Nectaries, which appear as small mounds with stomata on top, are formed at the base of the stamens, though their presence is variable (Smyth et al., 1990). The individual cells that constitute each organ are characteristic of the organ type, so that both overall structure and cellular identity can be used as criteria for organ type.

The development of the flowers has been described in detail, and divided into fourteen stages from the first appearance of a flower primordium to post-anthesis (Müller, 1961; Bowman et al., 1989; Hill and Lord, 1989; Smyth et al., 1990; Fig. 1A-D). Briefly, flower primordia arise in a phyllotactic spiral on the flanks of an indeterminate meristem (stages 1-2), individual organ primordia form in whorls from each flower primordium (stages 2-5), and finally the organ primordia morphologically differentiate during stages 7-12. It is during stages 2-7 when the identities of the floral organ primordia are thought to be specified (Bowman et al., 1991b). This spans the time when the organ primordia arise, but before they begin to morphologically differentiate. The inflorescence is a raceme, and an individual inflorescence may contain a complete developmental series of flowers, from the youngest primordium at the apex, to mature fruits toward the base.

\section{superman}

Similar phenotypes are observed for each of four recessive mutant alleles identified for the SUPERMAN locus. Each of the superman mutations causes defects in floral pattern primarily in the inner whorls of the flower, where there are alterations in both numbers and types of floral organs. Interior to the second whorl, an excess of staminoid organs with a partial or complete loss of the gynoecium is observed. The result is a flower with four sepals and four petals in the first and second whorls, a large and variable number of stamens developing interior to the second whorl (Fig. 1E-P), and in the center, an ovary of variable size and morphology. Since the phenotypes of each of the four mutations are similar, a detailed analysis is presented only for superman-1 (sup-1).

Flowers of plants homozygous for the sup-1 mutation have pattern defects interior to the third whorl (Fig. 1EP; Bowman and Meyerowitz, 1991; Meyerowitz et al., 1991). In wild-type flowers, six stamens and the central gynoecium occupy the region interior to the second whorl. In contrast, in sup-1 flowers, between 8 and 26 stamens (average 14.6;876 stamens in 60 flowers) and a gynoecium that is reduced and variable in structure are present interior to the second whorl (Fig. 11-M). The number of stamens produced decreases acropetally such that the first few flowers often have more than twenty stamens while the later ones may have only 8-10 stamens. Nectaries may be found at the base of the innermost as well as the outermost stamens.

The carpelloid organs at the center of sup-1 flowers were examined in 60 flowers (the first fifteen flowers produced on four different plants). The extremes ranged from a complete absence of carpelloid tissue in some flowers, to flowers with a nearly normal gynoecium interior to the extra stamens. There does not appear to be a correlation between the number of stamens produced and the amount or type of carpelloid tissue that develops in the first 15 flowers. However, normal gynoecia were observed most commonly in the more acropetal (after approximately 30 flowers were produced by an inflorescence meristem) flowers. No carpel tissue was observed interior to the extra stamens 

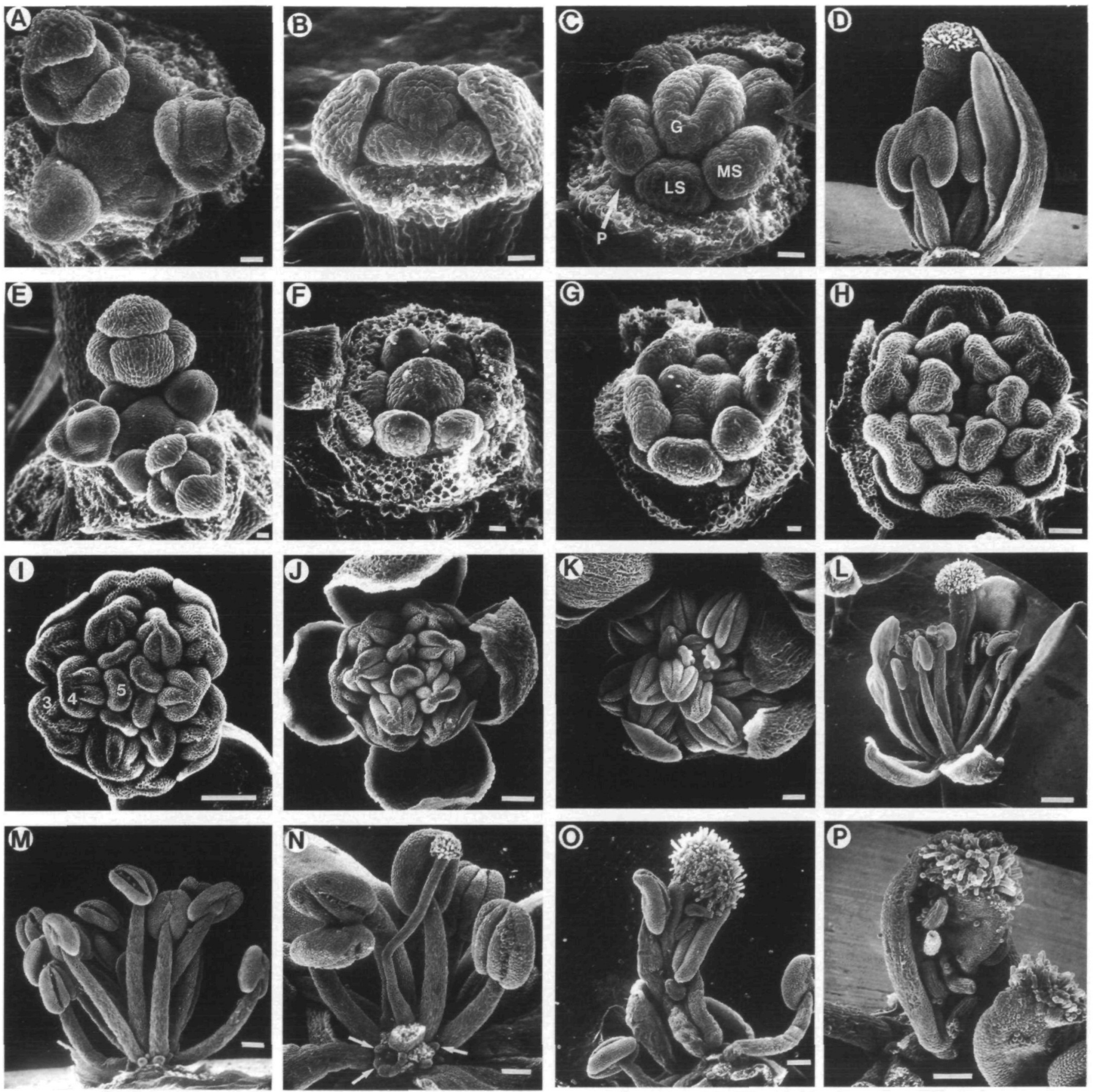

in $13 / 60$ flowers. Gynoecia consisting of one $(26 / 60$ flowers) or two (10/60 flowers) carpelloid organs are often present. These organs usually also have staminoid characteristics (see below). Alternatively, filamentous carpels lacking ovules and capped with stigmatic papillae (10/60 flowers; Fig. 1L) can develop. Filamentous organs with cellular morphology similar to stamen filaments, but capped with stigmatic papillae, are also observed (Fig. 1N). Occasionally, phenotypically nearly-normal gynoecia develop (1/60 flowers), allowing for self-fertilization.

The carpelloid organs that develop interior to the stamens are usually mosaics of carpel and stamen tissue

(45/46 carpelloid organs from above) and may be fused with the innermost stamens. In these organs, the regions of stamen tissue and carpel tissue are typically visible in large distinct sectors (Fig. 1O), with only two longitudinal sectors (one of each type) in the organ or, alternatively, small sectors of stamen tissue flanking a central carpelloid region. In the latter case ovules are produced not from the margin of the carpel tissue, but in a column in its center. These types of mosaic organs have a well defined boundary between stamen and carpel tissue. Occasionally, the sectors of stamen and carpel tissue are smaller and interspersed (Fig. 1P), similar to the third whorl organs of ap3-1 flowers 
Fig. 1. Scanning electron micrographs depicting the development of wild-type and superman-1 Arabidopsis flowers. In many cases the outer whorls of the flowers have been dissected away to reveal the inner whorls. (AD) Wild type. (A) Inflorescence meristem and flowers in stages 1-4 (Smyth et al., 1990). The sepal primordia have emerged on the two oldest flower buds. (B) Stage 6 flower. At this time all floral organ primordia have formed; the second whorl organ primordia are not visible in this view. (C) Stage 7-8 flower. Second whorl petal (P), third whorl lateral stamen (LS), third whorl medial stamen (MS), and fourth whorl gynoecium $(G)$ primordia are indicated. It is thought that the identity of each of the floral organ primordia is specified during stages 2-7. (D) Stage 12 flower showing the differentiated floral organs. (E-

P) superman-1. (E) Inflorescence meristem and flowers of stages 1-5. (F) Stage 6 flower. Up to this stage of development, sup- 1 flowers are morphologically indistinguishable from wild-type. (G) Stage 7-8 flower. Four organ primordia are developing in a whorled fashion on the flanks of the cells that would normally give rise to the gynoecium. (H) Stage 9-10 flower. Interior to the six third whorl stamens, a ring of five stamens and another ring of three stamens are visible. (I) Six stamens occupy their normal positions in the third whorl (3). Eleven additional stamens are evident, six forming a ring interior to the third whorl (4) and five more forming an additional ring (5). (J) Stage 11 flower. Six stamens, in addition to the normal third whorl of stamens, are present. (K) Stage 12 flower. Four distinct rings of stamens are visible.

(L) Mature superman-1 flower. Ten stamens and a central gynoecium lacking most of the ovary tissue are visible.

(M) The outer two whorls, the sepals and petals have been removed to reveal the thirteen stamens occupying the central region of the flower. (N) A filamentous structure, whose epidermal morphology is similar to that of stamen filaments, capped with stigmatic tissue occupies the center of this flower. Nectaries at the base of the third whorl and inner stamens are visible (arrows). (O) A mosaic organ with stamen and carpel sectors. Each sector is large, welldefined, and longitudinal. (P) Mosaic organ in which the sectors are small and less well-defined than those in $O$. $\mathrm{Bar}=10 \mu \mathrm{m}$ in A, B, C, E, F, and G: $30 \mu \mathrm{m}$ in $\mathrm{H} ; 100 \mu \mathrm{m}$ in $\mathrm{D}, \mathrm{I}, \mathrm{J}, \mathrm{K}, \mathrm{M}, \mathrm{N}, \mathrm{O}$, and $\mathrm{P} ; 300 \mu \mathrm{m}$ in $\mathrm{L}$.

(Bowman et al., 1989). Usually, only one or two of these mosaic organs occur in the same flower, although three or more have been observed infrequently.

The development of the first three whorls of sup-1 flowers is usually normal: four sepals, four petals, and six stamens form in their wild-type positions (Fig. $1 \mathrm{E}, \mathrm{F})$. However, the third whorl organ primordia occasionally vary in number (5-7), size and position. Interior to the third whorl, more primordia are produced from the region that in wild type develops into the gynoecial cylinder. The number (3-6) and position of these extra organ primordia is somewhat irregular (Fig. 1G-I). This process continues for a variable period of time; only a single additional ring or as many as four to five extra sequentially-formed rings of organ primordia, all of which develop into stamens (or sometimes carpelloid stamens in the case of the innermost organs), may be produced. Following the production of primordia that develop into stamens, the remaining floral meristem, if there is any, develops into carpelloid tissue (Fig. 1L, N-P). Often the carpel primordium is irregularly shaped and is congenitally fused to one of the innermost presumptive stamen primordia, resulting in the formation of a mosaic organ (Fig. 1O,P).

\section{Double and triple mutants of superman-1 and floral homeotic mutants}

superman-1 pistillata-1

The phenotype of sup-1 pi-1 flowers is the same as that of pi-I flowers (Bowman et al., 1989). The first whorl contains four wild-type sepals, while the second whorl is occupied by four smaller sepals. The remaining floral meristem, which in wild-type flowers gives rise to the third and fourth whorl organs, instead gives rise to an enlarged gynoecium composed of 2 to 4 carpels (mean 3.1, 198 carpels/63 flowers).

As shown in Fig. 2A-C, the development of sup-1 pi-1 flowers is indistinguishable from that of $p i-l$ flowers (Fig. 2D-E). The first whorl primordia are initiated in their normal positions and differentiate into sepals. The second whorl organ primordia are also initiated in the correct positions, but they differentiate inappropriately into small sepals, like those of $p i-1$ flowers (Fig. 2B, D). The remaining floral meristem, which ordinarily gives rise to the third and fourth whorl primordia, is incorporated into the developing ovary (Fig. 2C), as is observed in $p i-1$ flowers (Fig. 2E). This results in a gynoecium that is irregularly shaped and is composed of more than two carpels. Nectaries may form in the region between the second whorl organs and the gynoecium. Thus, $p i-1$ is epistatic to sup -1 and the loss of determinacy observed in sup- 1 flowers is eliminated in a pi-1 background.

\section{superman-1 apetala3-1}

An allelic series of apetala3 mutations has been described with ap3-3 (as well as ap3-4 and ap3-5) flowers representative of the most severe phenotype (Jack et al., 1992). ap3-3 flowers consist of two outer whorls of sepals, as in pi-1 flowers, while the organs of the inner two whorls, all of which are carpels, appear congenitally fused (Fig. 2F-G; Jack et al., 1992). In the weaker, temperature-sensitive ap3-1 allele (Fig. 2H), the third whorl organs develop as staminoid carpels and the fourth whorl develops into a normal gynoecium when grown at the restrictive temperature (Fig. 2I; Bowman et al., 1989). The molecular lesions of these two ap3 alleles are consistent with the severity of their phenotypes. ap3-3 is a nonsense mutation in the first coding exon, while ap3-1 is a mis-sense mutation in a conserved protein domain (Jack et al., 1992).

Flowers of plants homozygous for both sup-1 and ap3-1 grown at $25^{\circ} \mathrm{C}$ have two outer whorls of sepals surrounding several fused carpelloid structures that arise from the inner two whorls (Fig. 2J-O). The outer two whorls develop as described for ap3-1, ap 3-3 and sup-1 pi-1 flowers (above; Bowman et al., 1989). Cells that would normally form the medial third whorl organ primordia appear to be incorporated into an enlarged 

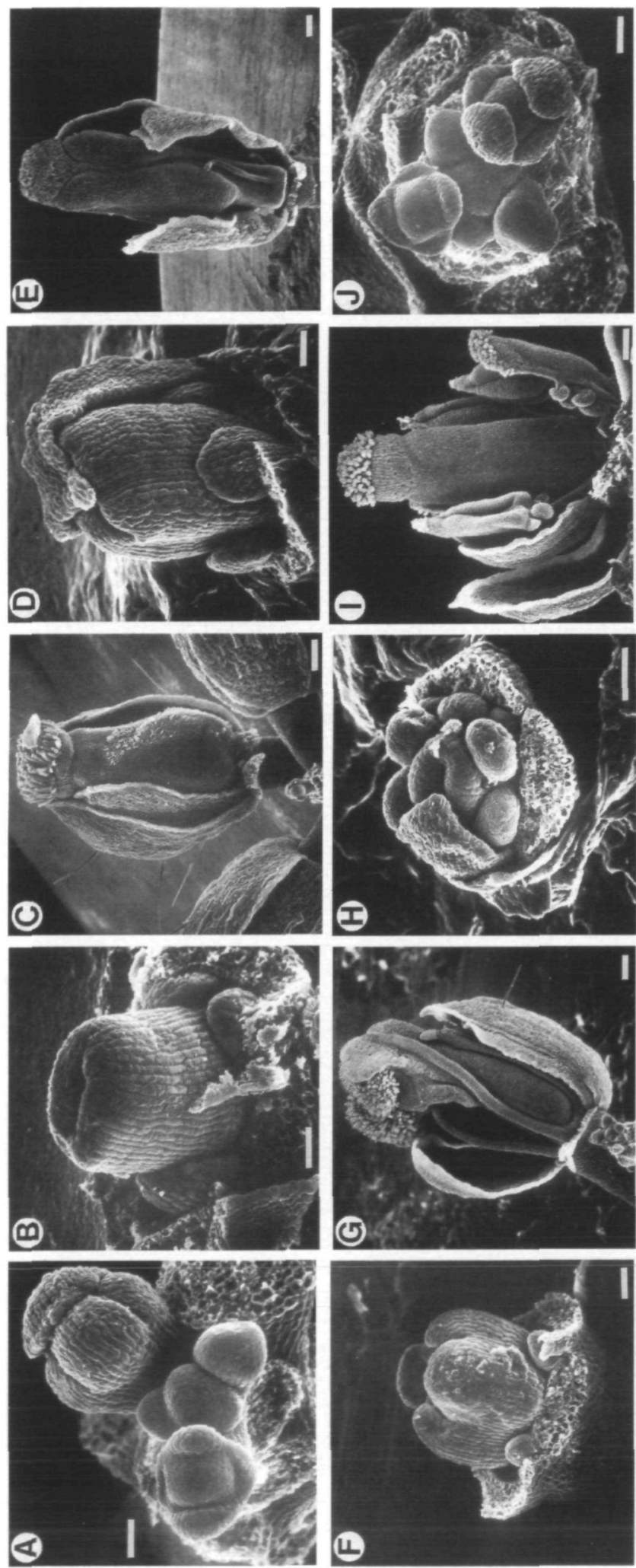
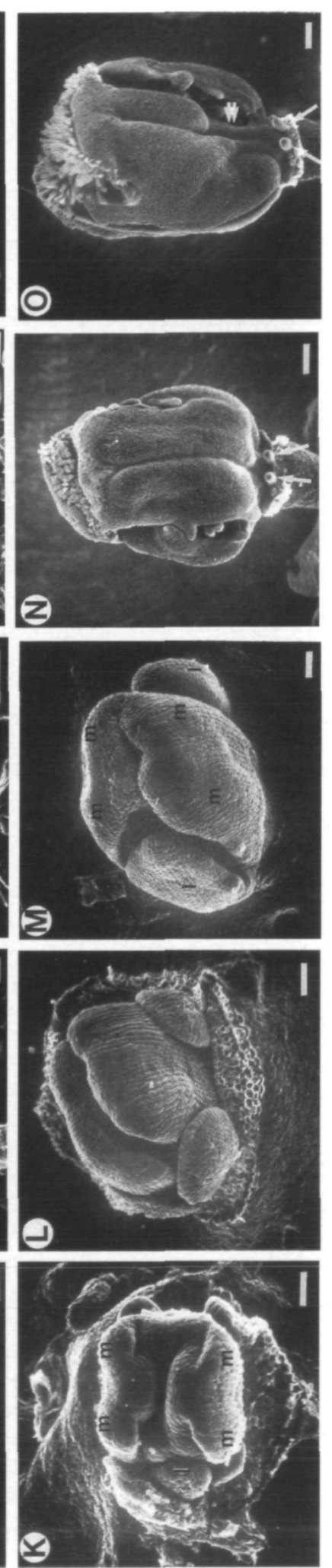

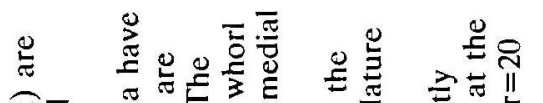

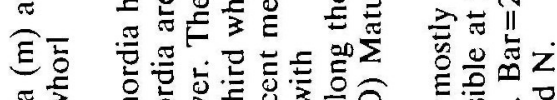

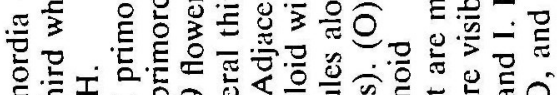

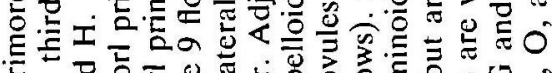

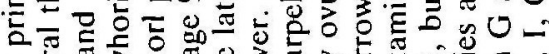

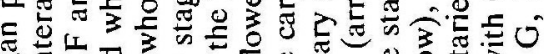

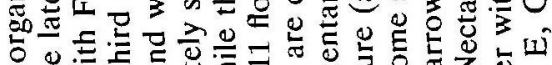
을

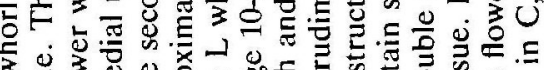

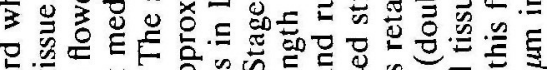

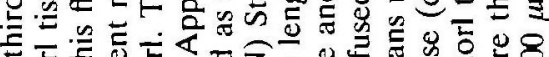

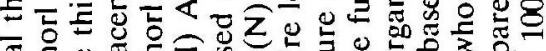

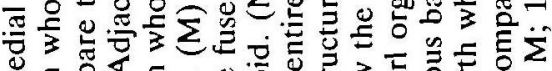

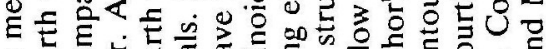

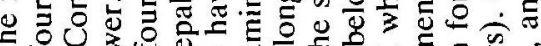
过

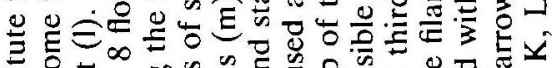

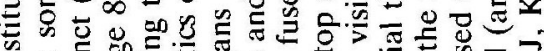

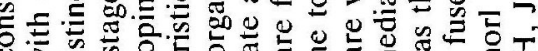

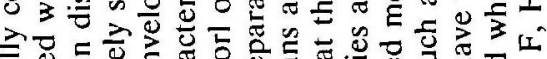

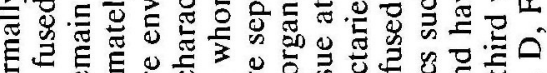

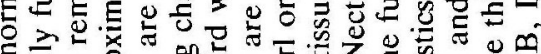
可.

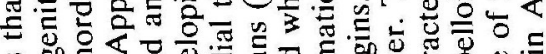
品

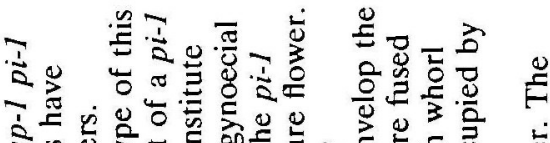

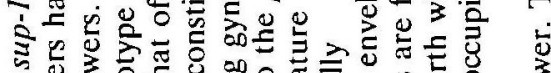

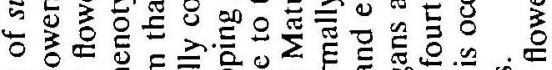

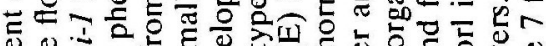

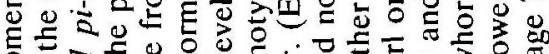

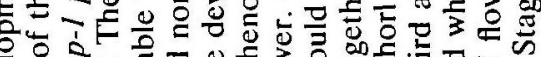

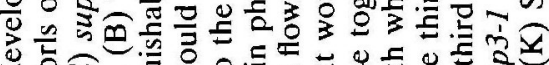
ช 0 \%

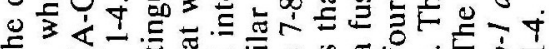
on

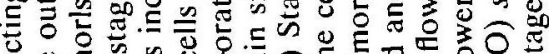

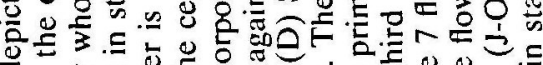
पै

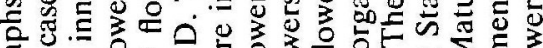

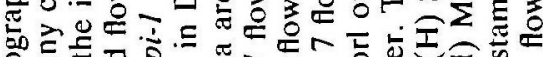

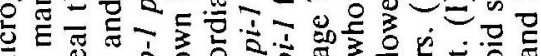

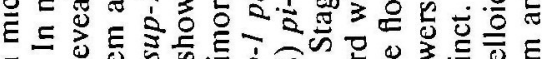

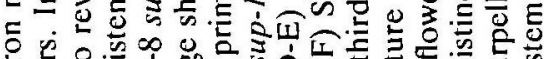

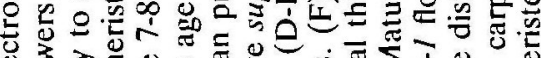

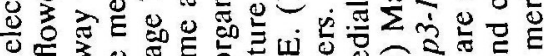

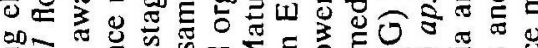
然

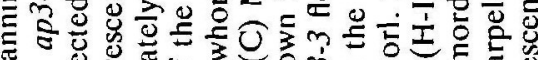
ऊ一. 4 s.s.

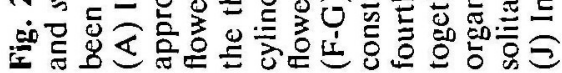



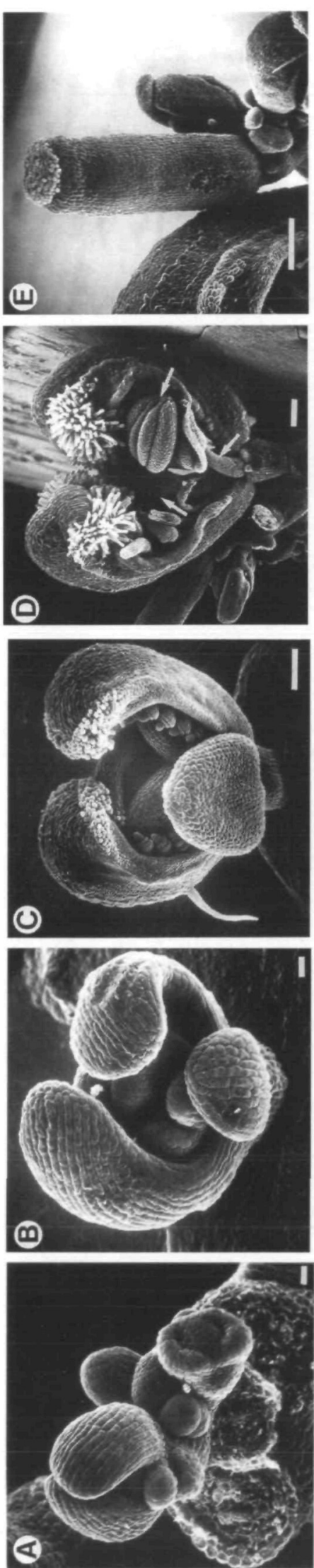
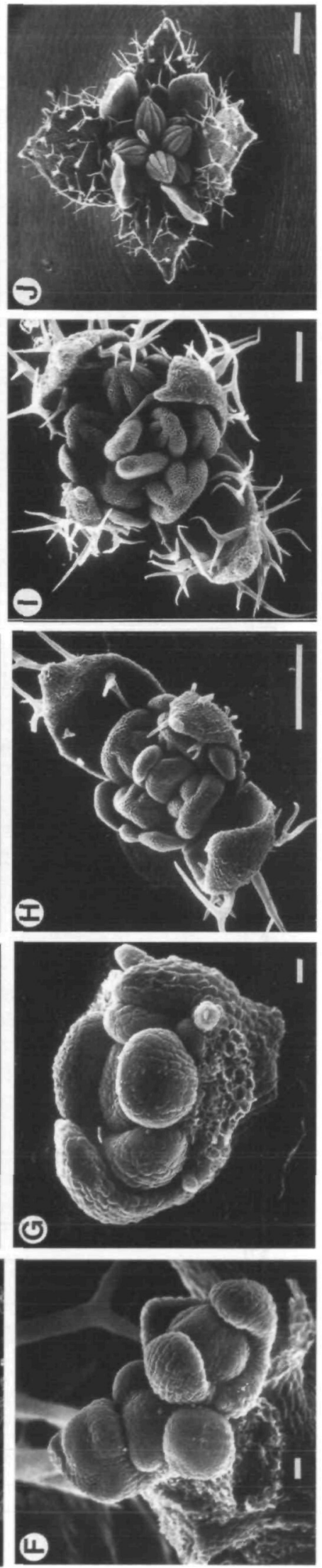

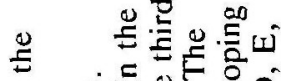

๑

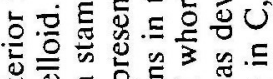

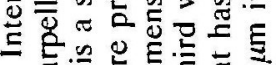

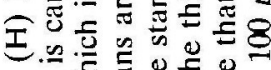

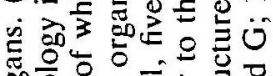

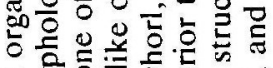

등

ह

है

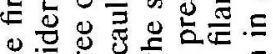

的至与.

पे

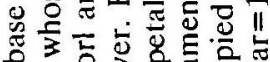

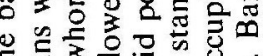

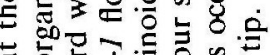

to

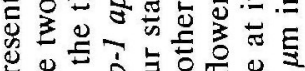

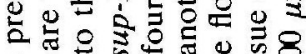

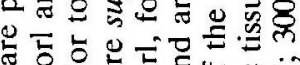

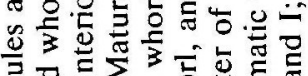

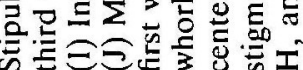

妾

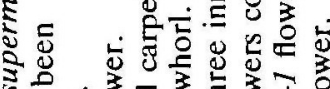

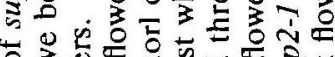

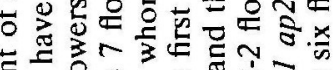

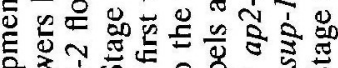

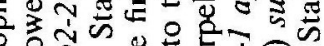

응 음을

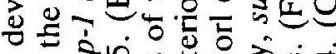

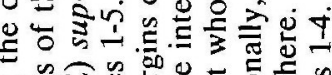

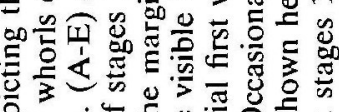

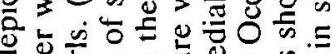

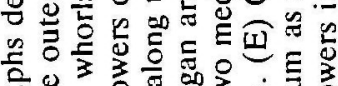

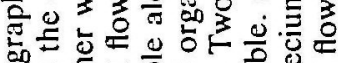

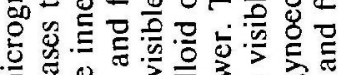

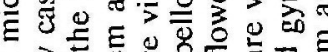

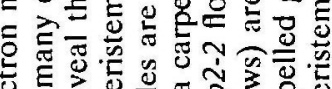

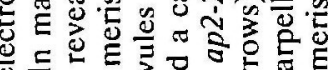

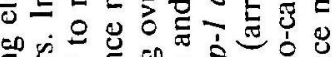

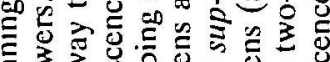

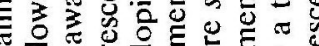

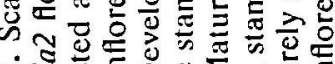
म

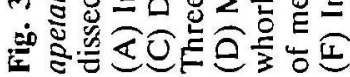


organ primordium that consists of the four medial third whorl organ primordia as well as those cells that usually constitute the fourth whorl gynoecium (Fig. 2K). Thus, the medial third whorl organ primordia are usually fused to each other and are frequently fused to the fourth whorl organ primordia (Fig. 2K-O). All of this tissue differentiates into carpelloid structures resulting in an abnormal gynoecium.

The fate of the lateral third whorl primordia is somewhat different. The lateral third whorl organ primordia usually remain distinct from the rest of the third whorl and the fourth whorl structures and differentiate into staminoid carpels (Fig. 2K, M, and N). However, in the later flowers produced by an inflorescence, the lateral third whorl organ primordia may be fused with medial third whorl organ primordia and the fourth whorl organ primordia. Nectaries may be found at the base of the fused third whorl organs (Fig. 2N-O). The extent of fusion of the medial third whorl and fourth whorl organs increases acropetally on the inflorescence, as does the extent of carpellody of the lateral third whorl organs. Similar trends are also observed in ap 3-1 flowers; the lateral third whorl organs are more staminoid than the medial, and the extent of carpellody of all third whorl organs increases acropetally.

The development of sup-1 ap3-1 doubly mutant flowers differs from ap 3-1 flowers, where the third and fourth whorl organs remain distinct (Fig. 2H-I). Rather, it resembles what is observed in ap3-3 flowers. The third and fourth whorl organ primordia of sup-1 ap3-1 flowers congenitally fuse, with the third whorl organs often enveloping the fourth whorl organs (Fig. $2 F-G)$. Thus, the sup-1 mutation enhances the weak, partial loss-of-function ap3-1 phenotype, causing the sup-1 ap3-1 double mutant to resemble closely the severe ap3-3 phenotype. Similar to the case for sup-1 pi1 flowers, the loss of determinacy in sup- 1 flowers is eliminated in an ap3-1 background.

superman-1 apetala2-2

Doubly mutant flowers of plants homozygous for both sup-l and ap2-2 exhibit a nearly additive phenotype (Fig. 3A-E). The outer two whorls resemble those of ap2-2 flowers (Bowman et al., 1991b), while the inner whorls resemble those of sup-1 flowers. The outer whorl of ap2-2 has carpelloid and phylloid organs; the second whorl has no organs. The third whorl of ap2-2 flowers is occupied by a severely reduced number of stamens ( 0.25 stamens/flower) and the fourth whorl is occupied by a two-carpelled gynoecium that is usually unfused.

The medial first whorl organs of sup-1 ap2-2 flowers are solitary carpels ( $52 / 78$ positions counted in 39 flowers), phylloid carpels (2/78), or mosaic organs with sectors of carpel and stamen tissue $(24 / 78)$. The stamen sectors of the mosaic organs always occupy the margins, while the carpel sectors occupy the central regions of the organs, as is observed in ap 2-2 flowers. The lateral first whorl organs are most often absent (43/78), but may be cauline leaf-like organs $(15 / 78)$, filamentous structures (17/78) or carpelloid leaves (3/78); again this is similar to what is observed in ap2-2 flowers. No second whorl organs are present.

The central region of sup-1 ap2-2 flowers is highly variable in phenotype in terms of number of organs present. On average 3 organs (118 organs/ 39 flowers) occupy this region of the flower, but from 0 to 6 organs were observed. The phenotypes of these organs are stamens (60/118 organs), carpelloid stamens (12/118), staminoid carpels (20/118), solitary carpels (14/118), and filamentous fused carpels lacking all internal structures and capped with stigmatic papillae (12/118). These carpelloid organs are similar to the carpelloid organs present in the center of sup-1 flowers. Normal, fully fused gynoecia were not observed. The outermost of these organs, those in the region that would normally be the third whorl, tend to be stamens, while the organs arising from the region that would ordinarily develop into the gynoecium are usually mosaics of both stamen and carpel tissue. The mosaic organs resemble those observed in sup-1 flowers. If more than one carpelloid organ is present, the carpelloid organs are usually fused to each other along the carpel tissue. The reduction in the numbers of organs occupying the inner whorls of ap 2-2 sup-1 flowers parallels that in singly mutant ap 2-2 flowers, which have a severe reduction in the number of third whorl organs.

The development of the outer whorl organs in sup-1 ap 2-2 flowers parallels that observed for ap2-2 flowers (Fig. 3A-E; Bowman et al., 1991b). The development of the central organs, in the third and fourth whorls, is variable. The organ primordia of these whorls are not produced in a consistent pattern and they are often fused congenitally (Fig. 3B-D). The development of these organs is similar to that observed for the innermost stamens and stamen-carpel mosaic organs of sup-1 flowers. Occasionally, when no second, third, or fourth whorl primordia are produced, the medial first whorl carpels are congenitally fused, resulting in a flower that consists only of a two- carpelled gynoecium (Fig. 3E). This has also been observed in ap2-2 flowers (Bowman et al., 1991b).

\section{superman-1 apetala2-1}

The outer two whorls of ap2-1 sup-1 flowers resemble those of ap2-1, while the inner whorls resemble those of sup-1 flowers (Fig. 3F-J). Thus, as in the other double mutant combination involving ap2 and sup alleles, the phenotype of sup-1 ap2-1 homozygotes is essentially an addition of the effects of the two single mutations. The outer two whorls of ap2-1 flowers are the same as described below for the double mutant. The third and fourth whorls of ap2-1 flowers are phenotypically normal except for reduced numbers and altered positions of third whorl stamens.

The first whorl of sup-1 ap2-1 flowers consists of four cauline leaf-like organs that may develop carpelloid features such as stigmatic papillae at their tips and rudimentary ovules along their margins, while the second whorl is occupied by organs with features of 
both stamens and petals, as in ap2-1 flowers. Interior to the outer two whorls, 4 to 9 stamens develop (average $6.8 ; 204$ stamens/ 30 flowers), fewer than are observed in sup-1 flowers. This parallels the reduced number of stamens found in ap2-1 singly mutant flowers (4.9 per flower; Bowman et al., 1989). The innermost stamens often have stigmatic tissue at their tips. The remainder of the flower consists of a variable amount carpelloid tissue similar to that observed in sup- 1 flowers. This tissue is usually a mosaic between carpel and stamen tissue ( 42 staminoid carpels $/ 30$ flowers). In only one of 30 flowers scored was no carpelloid organ present.

The development of sup-1 ap2-1 flowers is also similar to that of ap2-1 and sup-1 flowers (Fig. 3F-J). The outer two whorls develop as has been described for ap2-1 flowers (Bowman et al., 1989). Third whorl primordia develop in a similar fashion to that observed in ap 2-1 flowers: there may be fewer than six stamens, and they may arise in ectopic positions (Fig. 3G). Each of these primordia develops into a stamen. Interior to these stamens, usually 3 or 4 (range $0-4$ ) organ primordia arise (Fig. 3I-J), each of which develops into a stamen, although these organs often develop carpelloid characteristics, such as stigmatic tissue at their tips. Development interior to this is variable. In most cases one or two staminoid carpels or a filamentous structure capped with stigmatic papillae is produced, although occasionally the floral meristem stops proliferating following the development of the second ring of stamens (Fig. 3J). Thus, the number of stamens in both sup-1 ap2-2 and sup-1 ap2-1 is intermediate to that observed in sup-1 and the respective ap2 allele.

superman-1 agamous-1

Mutations at the $A G A M O U S$ locus cause indeterminate growth of the floral meristem as well as organ identity transformations. The outer two whorls of agamous flowers are phenotypically normal sepals and petals. In whorl 3, six petals develop in the positions normally occupied by stamens. In whorl 4 , the cells that would normally give rise to the gynoecium instead form another ag flower. This process repeats itself, resulting in the formation of an indeterminate number of whorls of floral organs in the pattern (sepals, petals, petals) (Bowman et al., 1989; 1991b).

Flowers of plants homozygous for both sup-1 and ag1 consist of a first whorl of sepals followed by an indeterminate number of petals. Observations of developing flowers elucidate the developmental basis of this phenotype (Fig. 4A-H). The first and second whorl organ primordia arise in the correct positions and numbers, as in sup-1 or ag-1 single mutants (Fig. 4A-B). These organ primordia subsequently differentiate into wild-type sepals and petals, respectively. The production of third whorl organ primordia, although usually normal, may be altered in a manner similar to that of the third whorl primordia of sup-1 flowers. As in ag-1 flowers, the organ primordia that arise in the second and third whorls are approximately the same size and each of these primordia develops into a petal (Fig. 4B). The remaining floral meristem, rather than behaving like another floral meristem as occurs in ag-1 flowers, continues to sequentially produce rings of organ primordia that subsequently develop into petals (Fig. 4C-E). The organ primordia in each of these later rings are variable in number (4-8) and position (Fig. 4C$E)$. This process continues indeterminately, resulting in an extreme double flower phenotype, and the ultimate ornamental Arabidopsis. Close examination of fully developed flowers reveals that some of the inner organs, while primarily petaloid in character, may have some sepaloid characteristics such as stomata, and some sepaloid epidermal cells (Fig. 4H). These sepaloid characters are random in their frequency and position, in contrast to the large longitudinal sepaloid sectors of ag-1 singly mutant flowers, which occur every third whorl in ag-1 flowers (Bowman et al., 1989).

Both single mutations, sup-1 and ag-1, cause indeterminate growth to varying extents. In sup-1 ag- 1 flowers, fasciation of the floral meristem may occur with the meristem becoming enlarged (over $100 \mu \mathrm{m}$ in width) and elongated in shape. Organ primordia, all of which develop into petals, are produced along the entire margin of the fasciated meristem (Fig. 4F-G). Thus, the two mutations interact synergistically to cause greatly increased, indeterminate growth of the floral meristem.

sup-1 ag-1 double mutant flowers are easily distinguished from ag- 1 flowers due to the differences in growth rates of sepals and petals. In $a g-1$ flowers, the sepals that arise in the fourth whorl rapidly dwarf the adjacent developing petals and grow to cover the floral meristem forming a structure resembling an internal flower bud (Bowman et al., 1989). In contrast, all of the primordia (except those of the first whorl) of sup-1 ag-1 flowers develop into petals, and all have the same slow growth rate characteristic of petals. The result is that the floral meristem is not covered by developing organs, and it is exposed even in relatively old flowers (Fig. 4F).

\section{superman-1 agamous-2}

Mutations at the ERECTA locus have a profound effect on the overall morphology of ag flowers (Bowman et al., 1991b). In an erecta mutant background, there is little elongation of the pedicel between whorls of $a g$ flowers. However, in a wild-type ERECTA background, the pedicel elongates after every third floral whorl, or just prior to the whorls of sepals, in ag flowers (Yanofsky et al., 1990). To determine whether the ERECTA locus has an effect on the elongation of the pedicel of sup ag flowers, a sup-1 ag-2 double mutant was constructed in a wild-type ERECTA background The phenotype of sup-1 ag-2 ERECTA flowers is the same as that of sup-1 ag-2 erecta flowers. Thus, in contrast to $a g-2$ flowers, there is no pedicel elongation between any of the floral organs in sup-1 ag-2 flowers, corroborating the conclusion that no new flower is formed in the fourth whorl in sup-1 ag-2 flowers.

\section{superman-1 agamous- 1 apetala2-1}

The overall architecture of sup-1 ag-1 ap2-1 flowers is similar to sup-1 ag-1 flowers, but with minor differences 

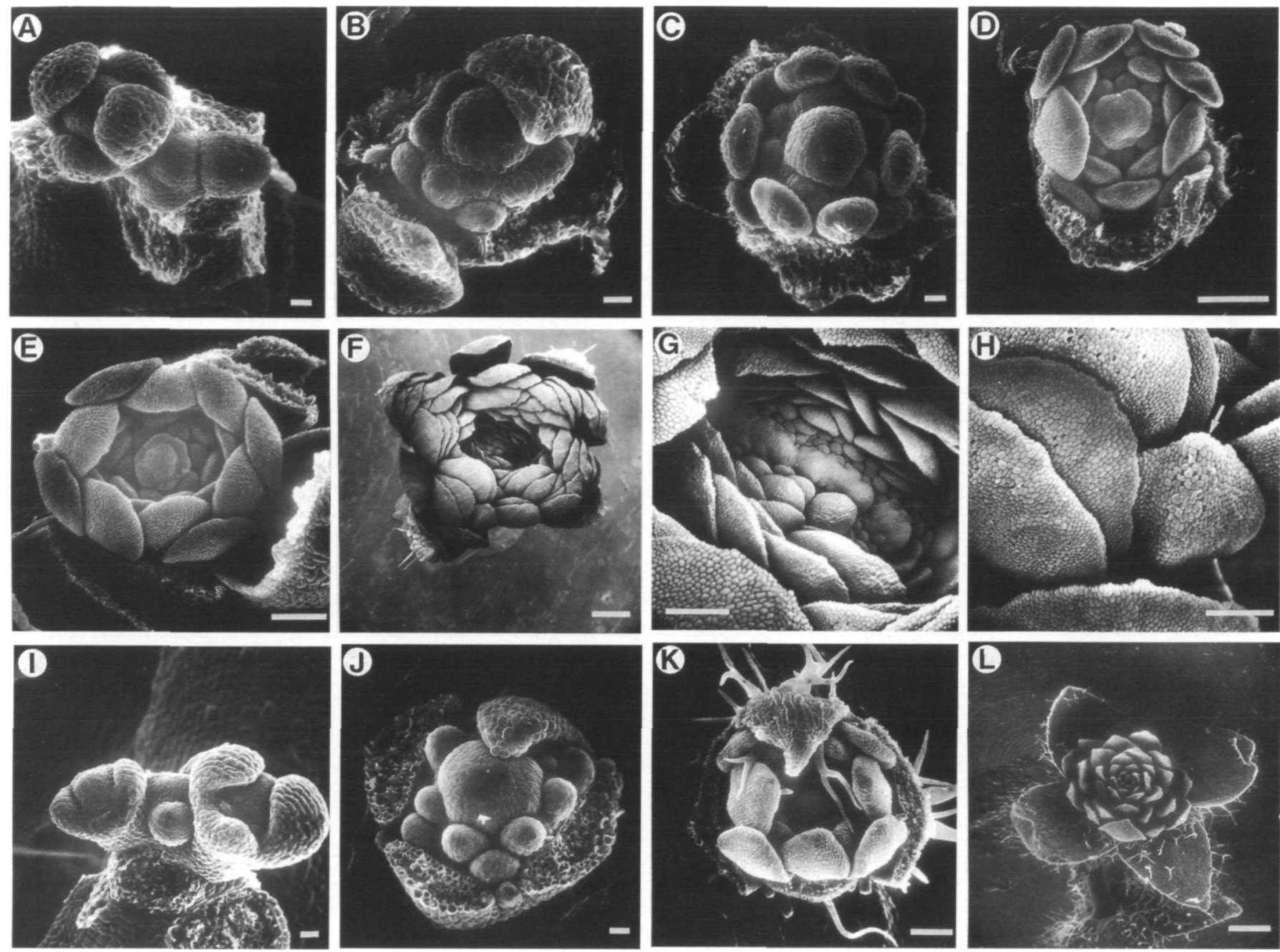

Fig. 4. Scanning electron micrographs depicting the development of sup-1 ag-1 and sup-1 ag-1 ap2-1 flowers. In many cases the outer whorls of the flowers have been dissected away to reveal the inner whorls. (A-H) sup-1 ag-1 flowers. (A) Inflorescence meristem and flowers in stages 1-4. (B) Stage 6 flower. At this stage, sup-1 ag-1 flowers resemble wild type except that the second and third whorl organ primordia are similar in size, as observed in ag-1 flowers. (C) Six organ primordia are present interior to the third whorl and the floral meristem is pentagonal. (D) Eight organ primordia are present along the margins of the irregularly shaped floral meristem. (E) The floral meristem continues to produce organ primordia along its margins. (F) sup-1 ag-1 flower of late developmental stage. (G) The floral meristem of flower shown in $F$ has become enlarged and elongated, producing organ primordia along its entire circumference. $(\mathrm{H}) \mathrm{Close} u p$ of inner organs of sup-1 ag-1 flower. Many stomata are visible as well as a sector of sepaloid tissue (arrow). (I-L) sup-1 ag-1 ap2-1 flowers. (I) Inflorescence meristem and flowers in stages 1-5. (J) Stage 6-7 flower. Organ primordia of the third whorl are not in the normal positions and the floral meristem is enlarged. (K) The first whorl cauline leaf-like organs have developed stellate trichomes, while all the inner organs are staminoid petals. (L) Mature sup-1 ag-1 ap2-1 flower. Bar $=10 \mu \mathrm{m}$ in $\mathrm{A}$, $\mathrm{B}, \mathrm{C}, \mathrm{I}$, and $\mathrm{J} ; 50 \mu \mathrm{m}$ in $\mathrm{D}, \mathrm{E}$, and $\mathrm{K} ; 100 \mu \mathrm{m}$ in $\mathrm{G}$ and $\mathrm{H} ; 300 \mu \mathrm{m}$ in $\mathrm{F}$ and $\mathrm{L}$.

(Fig. 4I-L). For instance, the second whorl primordia do not always form in the triply mutant flowers, probably due to the ap2-1 mutation, since loss of second whorl organs also occurs in ap2-1 and ap2-1 ag-1 flowers. Additionally, the pattern (numbers and positions) of third whorl, and subsequent, organ primordia formation is more often irregular in sup-1 ag-1 ap2-1 flowers (Fig. 4J; altered third whorl positions are also observed in ap2-1 and ap2-1 ag-1 flowers).

The identity of the organs in sup-1 ag-1 ap2-1 flowers resembles those of ag-1 ap2-1 flowers (Bowman et al., 1989 ) except that the leaf-like organs that occur in inner whorls of ag-1 ap2-1 flowers are not present in the triply mutant flowers. The first whorl organs of sup-1 ag-1 ap2-1 flowers are cauline leaves with some carpelloid characteristics, as is observed in the first whorl of $a g-1$ ap2-1 flowers (Fig. 4F,L). All organs interior to the first whorl (a large, indeterminate number) in the triply mutant flowers are staminoid petals, like those occupying the second and third whorls of ag-1 ap2-1 flowers (Fig. 4F,L; Bowman et al., 1989). Thus, the pattern of organs in the triple mutant is similar to that in sup-1 ag1 flowers, while the identity of the organs is like that observed in ag-1 ap2-1 flowers. 
Expression patterns of floral homeotic genes in superman-1 flowers

The phenotype of superman flowers suggests that the $S U P E R M A N$ gene product may be a regulator of floral homeotic genes. The epistatic interactions of $a p 3$ and $p i$ mutants with sup mutants and the synergistic interaction between ag mutants and sup mutants identify these genes as candidates for genes regulated by SUPER$M A N$. To determine if the expression patterns of the two cloned Arabidopsis floral homeotic genes, AP3 (Jack et al., 1992) and $A G$ (Yanofsky et al., 1990), are altered in a superman genetic background, we performed tissue in situ hybridizations to sections of developing flowers using $A P 3$ and $A G$ probes. The SEM micrographs in Figures $1-4$ provide a visual guide for the tissue sections of Figures 5 and 6.

The expression of APETALA3 is altered in superman-1 flowers

The expression pattern of the $A P 3$ gene in both wildtype and homeotic mutant flowers has been described by Jack et al. (1992). Briefly, in wild-type flowers, $A P 3$ expression commences during stage 3 (see Fig. 1A), before the appearance of the second and third whorl primordia, and is restricted to floral whorls two and three, the whorls affected in ap 3 mutants (Fig. 5A-D; Jack et al., 1992). During stages 3-4, a uniform signal is detected throughout the region of the floral meristem that will later give rise to the second and third whorl organ primordia (Fig. 5A-B). When the second and third whorl organ primordia morphologically differentiate from the floral meristem during stage 5 , the signal is confined to those organ primordia and cells directly underlying the primordia (Fig. 5A-B). As differentiation of the second and third whorl organ primordia progresses, into petals and stamens, respectively, (stages 7-14), the uniform spatial expression pattern is maintained, although the intensity of the signal diminishes compared to that of stage 3 (Fig. 5C-D), with the expression in the second whorl petals persisting longer than that in the third whorl stamens.

The initial spatial pattern (stages 3-4) of $A P 3$ RNA in superman-1 flowers is strikingly different from that observed in wild-type flowers. In addition to those cells developing into the second and third whorls, the hybridization signal is expanded to include most of the cells that constitute the fourth whorl in wild-type flowers (Fig. 5E-F). A narrow band of cells, one to four cellular rows wide, at the center of the floral meristem has no detectable signal above background. Thus, the initial inner boundary of $A P 3$ expression has been shifted towards the center of the floral meristem. During stages 5-6, when the second and third whorl organ primordia emerge, $A P 3 \mathrm{RNA}$ is detected in these primordia (Fig. 5E-F). However, AP3 RNA is also detected in cells interior to the third whorl primordia, which develop into gynoecial tissue in wild-type flowers, but develop into additional stamens in sup-1 flowers (Fig. 5E-H). Again, no signal is detected at the center of the floral meristem. Following stage $6, A P 3$ RNA is detected in the additional organ primordia that form interior to the third whorl (Fig. 5I-J); each of these primordia differentiates into a stamen. This pattern continues, with expression interior to the youngest organ primordia commencing just before the next organ primordia morphologically differentiate from the floral meristem (similar to initial AP3 expression in the second and third whorls of wild-type flowers), until the floral meristem ceases to proliferate (Fig. 5G-H). Thus, the spatial pattern of $A P 3$ expression expands into the fourth whorl to include the extra stamens in superman-1 flowers.

The spatial and temporal pattern of $A P 3$ RNA detected in sup-1 ag-1 flowers is similar to that observed for sup-1 flowers. During stages $3-6, A P 3$ RNA is detected in a pattern indistinguishable from that described for sup-1 flowers. The signal is associated with the second and third whorl primordia, as well as the more abaxial cells of the floral meristem interior to the third whorl (Fig. 5K-L). Following this, the floral meristem produces an indeterminate number of organ primordia, all of which exhibit a hybridization signal that appears on the flanks of the floral meristem before the primordia arise and is uniform throughout the organ primordia once formed (Fig. 5M-N). Each of the organ primordia that develops interior to the first whorl differentiates into a petal (Fig. 4F). The central region of the indeterminate floral meristem of sup-1 ag-1 flowers, one to several rows of cells wide, exhibits no signal above background throughout flower development, similar to that observed for the floral meristem of sup- 1 flowers (compare Fig. $5 \mathrm{~F}$ and $5 \mathrm{H}$ to $5 \mathrm{~L}$ and $5 \mathrm{~N}$ ).

\section{AGAMOUS expression is unaltered in superman-1 flowers}

The floral specific expression pattern of the $A G$ gene, in both wild-type and homeotic mutant flowers, has been described by Drews et al. (1991) and Bowman et al. (1991a). Briefly, in wild-type flowers, $A G$ expression is restricted to whorls three and four, the whorls affected in ag mutants, and commences during stage 3 (see Fig. $1 \mathrm{~A}$ ), before the appearance of the third and fourth whorl primordia (Fig. 6A-B; Drews et al., 1991). A uniform signal is detected throughout the region of the floral meristem that will give rise to the third and fourth whorl organ primordia during stages 3-4. When the third and fourth whorl organ primordia emerge from the floral meristem during stage 5 , the signal is confined to those organ primordia and cells directly underlying the primordia. As cellular differentiation of the third and fourth whorl organ primordia progresses, into stamens and carpels, respectively, (stages 9-14), $A G$ expression is localized to those organs (Fig. 6C-D) and becomes progressively restricted to certain cell types within these organs, such as stigmatic papillae, endothelial cells and endothecial cells (Bowman et al., 1991a).

The spatial and temporal pattern of $A G$ expression is not significantly altered in sup-1 flowers. During stages 3-4, the distribution of $A G$ RNA is relatively uniform in the floral meristem in those regions that will give rise to the organs interior to the second whorl, the same 
Fig. 5. Expression of APETALA3 RNA in wild-type, sup-1 and sup-1 ag-1 flowers. Each section was photographed in two ways: bright field exposure $(A, C, E, G, I, K, M)$ and bright field - dark field double exposure $(B, D, F, H, J, L$, $\mathrm{N})$ using a yellow filter during the dark field exposure causing the silver grains (RNA hybridization signal) to appear yellow. All flowers are oriented with the apex of the flower towards the top. In E-H and $\mathrm{K}-\mathrm{N}$ the floral meristem is indicated $(\mathrm{fm})$ and is the region between the arrows.(A-D) Wild-type flowers. (A and B) This series shows a section through stage 4 and stage 6 wild-type flowers. AP3 RNA is detected in the regions of the floral meristem (f) destined to give rise to the second and third whorl organs, but not in the sepal primordia (sp) of the stage 4 flower. At stage 6, AP3 RNA is detected in the petal (p) and stamen (st) primordia, occupying the second and third whorls respectively, but not in the sepals (se) and carpels (c) in the first and fourth whorls. A similar pattern is seen in the other stage 6 flower in the right side of the frame. (C and D) Late in development, after morphological differentiation of the floral organs has commenced, AP3 RNA is detected in the maturing petals (p) and stamens (st), but not in the sepals (se) or carpels (c). (E-J) sup-1 flowers. (E and F) This series depicts stage 4 (right) and stage 6 (left) sup-1 flowers. The inner boundary of $A P 3$ RNA expression is shifted towards the center of the floral meristem (f) of the stage 4 flower, such that $A P 3$ RNA is detected in cells interior to those that are the precursors of the second and third whorl organs. This is in sharp contrast to what is seen in wild-type (A and B) where the entire floral meristem interior to the third whorl organ primordia consists of non- $A P 3$-expressing cells. As in wild-type, no signal is seen in the sepal primordia (sp). In the stage 6 flower, $A P 3$ RNA is detected in the second whorl petal (p) and third whorl stamen (st) primordia. In addition, $A P 3$ RNA is present in cells on the flank of the remaining floral meristem (fm) which in wild type gives rise to the fourth whorl carpels but in sup-1 flowers gives rise to extra stamens. No signal is detected in the sepals (se).
( $\mathrm{G}$ and $\mathrm{H}$ ) In this approximately stage 8 flower, $A P 3$ RNA is detected in the second whorl petal (p) and third whorl stamen (st) primordia. In addition, $A P 3$ RNA is detected in regions of the floral meristem ( $\mathrm{fm}$ ) from which additional stamen primordia will form prior to their emergence. In the lower right of the panel $A P 3$ RNA is detected nearly throughout the floral meristem (f) of a stage 4 flower. (I and J) This series shows a section through a sup-1 flower in which morphological differentiation has commenced in the third whorl (3st) and additional (4st) stamens. $A P 3 \mathrm{RNA}$ is present in all of the stamens as well as the second whorl petals (p). A lower signal is associated with the organ primordia in the center of the flower. The fate of these central organ primordia varies from stamens to carpels, with mosaic organs occurring most frequently. (K-N) sup-1 ag-1 flowers. (K and $\mathrm{L}$ ) This series shows a section through a stage 5 flower (left) and an older flower (right). AP3 RNA is detected nearly throughout the floral meristem (f) of the stage 5 flower as well as all the organ primordia ( $p$ ) present interior to the first whorl sepals. Simlarly, $A P 3$ RNA is observed in all the organ primordia interior to the first whorl in the older flower as well as the region of the floral meristem (fm) from which the next organ primordia will emerge. All organ primordia, except the first whorl, will differentiate into petals. ( $\mathrm{M}$ and $\mathrm{N}$ ) This series shows a section through an approximately stage 8 flower. Two petal primordia (p), occupying the second and third whorls are visible in addition to very small primordia nestled between the third whorl organ primordia and the floral meristem ( $\mathrm{fm}) . A P 3 \mathrm{RNA}$ is detected in all organs and organ primordia interior to the first whorl, as well as the flanks of the floral meristem $(\mathrm{fm})$. The floral meristem is indeterminate, continuing to produce organ primordia, all of which differentiate as petals. In nearly all cases $A P 3$ RNA is detected in those cells on the flank of the floral meristem from which the organ primordia are produced. Bars $=50 \mu \mathrm{m}$ pattern seen in wild-type flowers at this stage of development (Fig. 6E-F). As the third and additional interior rings of organ primordia are produced in sup-1 flowers, $A G$ RNA continues to be detected in the additional whorls of organ primordia and throughout the entire floral meristem from which they are derived (Fig. 6E-H). Later in development, $A G$ RNA is detected in the same cell types with which it is associated in wild-type flowers. A high signal is present in nectaries, the connectives and endothecia of anthers, and the occasional ovules and stigmatic tissue that develop on carpelloid organs at the center of sup-1 flowers.

\section{Discussion}

In contrast to the floral homeotic mutants, the alterations in flower structure observed in superman mutants are not strictly homeotic conversions of floral organs. Although additional stamens develop at the expense of carpels in sup-1 single mutants, the fact that carpels develop in the first whorl of sup-1 ap2-2 doubly mutant flowers indicates that the $S U P E R M A N$ gene product is not required for carpel development. Rather, the genetic and molecular data show that SUPERMAN has a role in the spatial regulation of at least one floral homeotic gene.

\section{Homeotic genes}

Based on a series of genetic experiments, it has been proposed that the four floral homeotic genes, $A G A$ $M O U S, A P E T A L A 2, A P E T A L A 3$ and PISTILLATA, act alone and in combination to determine in large part the specification of floral organ identity (Bowman et al., 1991b). The precise spatial expression patterns of the floral homeotic genes are proposed to represent positional information within the developing flower. Each of the four genes is proposed to act in two adjacent whorls of the flower, and thus, falls into one of three classes: those that affect the outer two whorls ( $A P E T A L A 2$ ), those that act upon the second and third whorls ( $A P E T A L A 3$ and PISTILLATA), and those that exert their influence on the inner two whorls (AGAMOUS). The three classes demonstrate the division of the flower primordium into four regions with each region, or whorl, having in wild type a unique 

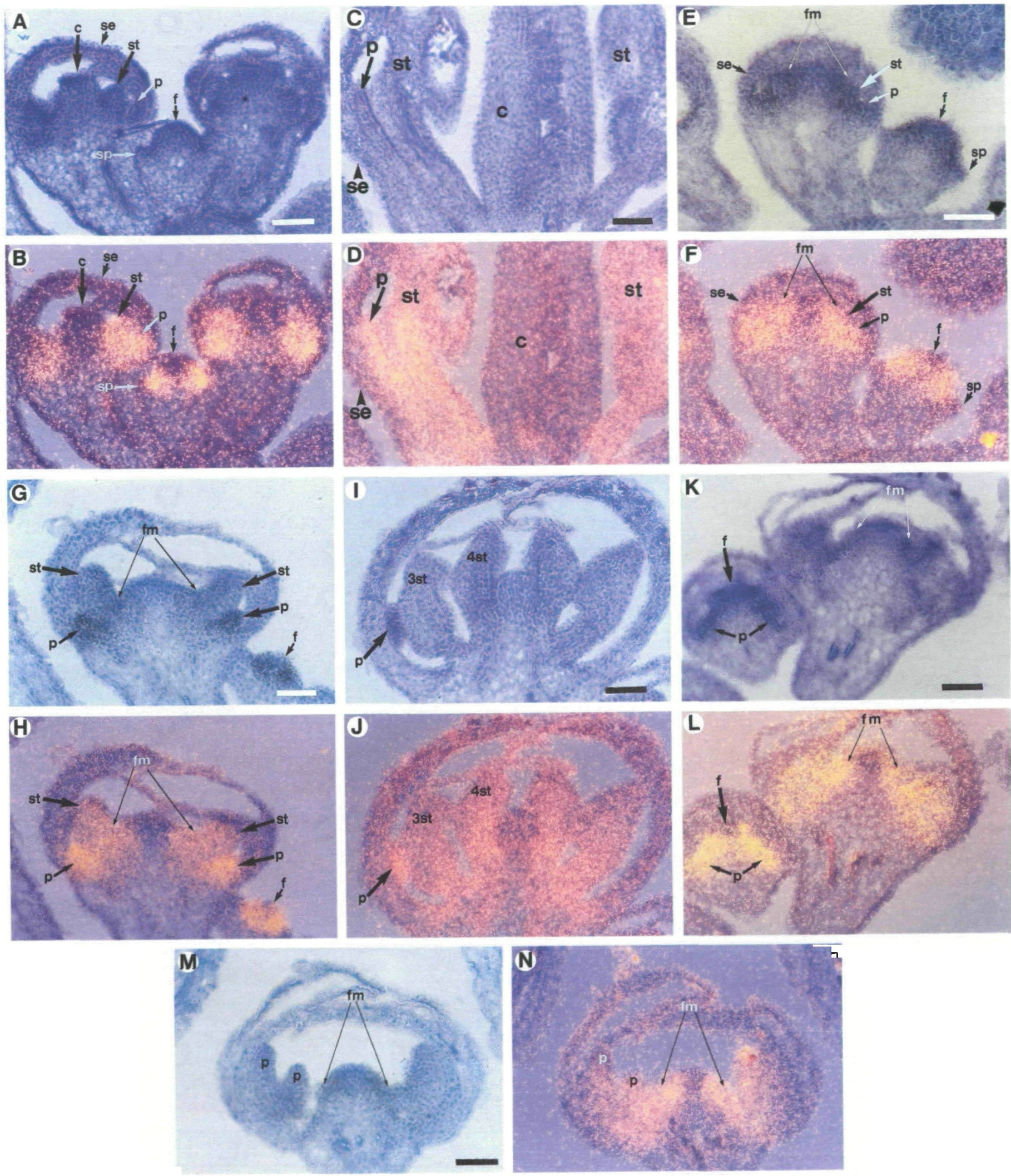

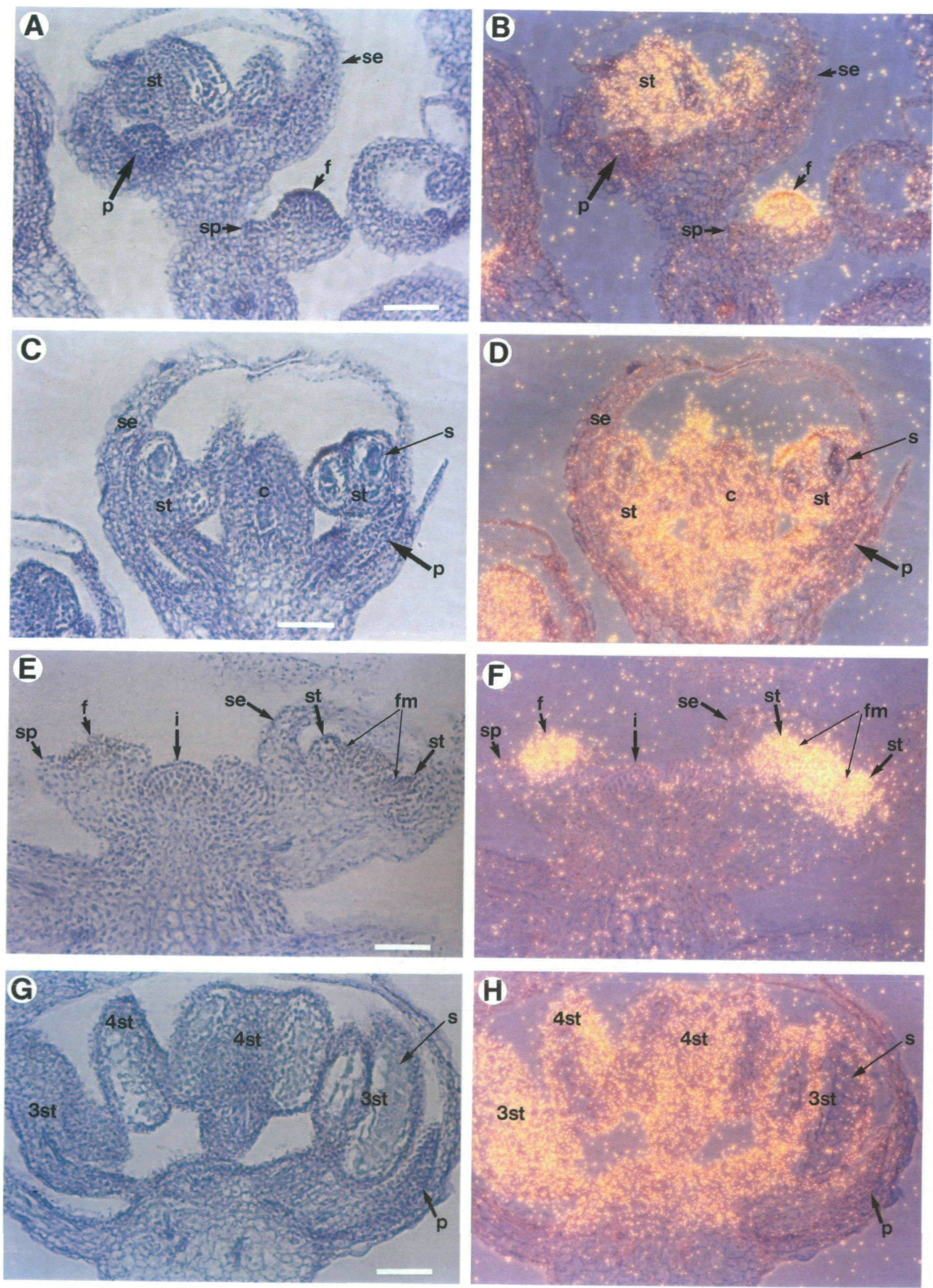
Fig. 6. Expression of AGAMOUS RNA in wild-type and sup-1 flowers. Each section was photographed in two ways: bright field exposure (A, C, E, G) and bright field - dark field double exposure $(B, D, F, H)$ using a yellow filter during the dark field exposure causing the silver grains (RNA hybridization signal) to appear yellow. All flowers are oriented with the apex of the flower towards the top. In $E$ and $F$ the floral meristem is indicated ( $f m$ ) and is the region between the arrows. (A-D) Wild-type flowers. (A. and $B$ ) This series shows a section of a stage 4 flower (right) and an older flower (left). $A G$ RNA is detected in the regions of the floral meristem (f) that will give rise to the third and fourth whorl organs, but not in the first whorl sepal primordia (sp) of the stage 4 flower. In the older flower, $A G$ RNA is restricted to the stamens (st) and carpels (not shown in this section) while no signal is detected in the first whorl sepals (se) and second whorl petals (p). (C and D) Late in development, after morphological differentiation of the floral organs has commenced, $A G$ RNA is detected in the third whorl stamens (st) and fourth whorl carpels (c), but not in the first whorl sepals (se) and second whorl petals (p). Note that $A G$ RNA is already becoming restricted to certain cell types as there is no $A G$ RNA detectable in the

sporogenous tissue (s) of the stamens. (E-H) sup-1 flowers ( $E$ and $F$ ) This series shows a section through stage 3 and 5 flowers as well as the inflorescence meristem. Similar to $A G$ expression in wild-type flowers, $A G$ RNA is detected in the regions of the floral meristem (f) that will give rise to the third whorl and inner organs, but not in the sepal primordia (sp) of the stage 3 flower. In the stage 5 flower, $A G$ RNA is detected in the third whorl stamen primordia (st) and throughout the floral meristem (fm) which will give rise to the extra stamens, but not in the first whorl sepals (se). As in wild-type (Drews et al., 1991), no signal is detected in the inflorescence meristem. ( $\mathrm{G}$ and $\mathrm{H}$ ) Later in development, $A G$ RNA is detected in all organs interior to the second whorl. In this section, $A G$ RNA is detected in the third whorl (3st) and interior (4st) stamens, but not in the first whorl sepals and second whorl petals (p). In both the third whorl and inner stamens, $A G$ RNA is becoming restricted to the same cell types as in wild type. For example, there is no detectable signal in the sporogenous tissue (s). Bars $=50 \mu \mathrm{m}$.

combination of homeotic gene products present. Each of these regions then follows an organ-specific developmental pathway directed by different combinations of floral homeotic gene products as shown in Fig. 7. In support of this model, the expression patterns of the two cloned homeotic genes, $A G A M O U S$ and $A P E$ $T A L A 3$, are consistent with their proposed role in this model of floral organ specification; in wild-type flowers $A G$ expression is restricted to the third and fourth whorls, and $A P 3$ expression is restricted to the second and third whorls (Yanofsky et al., 1990; Drews et al., 1991; Jack et al., 1992).

A major question that arises is, how do these floral homeotic genes come to be expressed in their precise spatially and temporally restricted patterns? It is clear that cross-regulatory interactions between the homeotic genes are in part responsible for defining the spatial domains of activity of some of the floral homeotic genes. For example, the proposed mutually antagon- istic interactions between $A G$ and $A P 2$ (Bowman et al., $1991 \mathrm{~b})$, which have been shown to be executed at the RNA level for $A G$ (Drews et al., 1991), result in helping to define the spatial boundary of expression of $A G$. However, cross-regulatory interactions are insufficient to account for the localization of the $A P 3$ and $P I$ activities. That $A P 3$ is initially expressed in a welldefined temporal and spatial manner in wild type as well as in other homeotic mutants (Jack et al., 1992), suggests that it may be responding to factors that are present prior to the other homeotic gene products. The phenotype of sup flowers suggests that $S U P$ is at least partially responsible for defining the initial expression patterns of $A P 3$ and/or $P I$.

\section{The role of SUPERMAN}

If the primary role of $S U P E R M A N$ is to suppress AP3/PI activity in the fourth whorl, certain predictions can be made about doubly mutant strains with sup and the homeotic mutations, and these are shown in Fig. 7. Since ap2 mutations primarily affect organ specification in the outer two whorls and SUP acts in the fourth whorl, additive interactions should be observed in sup ap2 flowers. This is the case in sup-1 ap2-2 flowers. The outer two whorls resemble those of ap2-2 flowers while the inner whorls are occupied by an increased number of stamens (relative to the number in ap 2-2 flowers) and a reduced amount of carpel tissue. Since ap 2 mutations cause a severe reduction in the number of third whorl organs, the number of staminoid organs produced in sup-1 ap2 flowers is intermediate between the number produced in sup- 1 flowers and the number produced in ap2 flowers (Bowman et al., 1991b).

In sup ag flowers, we predict that AP2 is active in all whorls due to the absence of AG activity, and AP3/PI activity expands into all whorls except the outermost whorl due to the absence of SUP activity. Therefore, sup ag flowers are expected to consist of an outer whorl of sepals with an indeterminate number of whorls (due to the indeterminate nature of ag flowers) of petals interior to the sepals. These predictions are validated by the phenotype of sup ag flowers (Fig. 4A-H) and the expression pattern of $A P 3$ in sup ag flowers (Fig. $5 \mathrm{~K}-\mathrm{N}$; see below). Similar arguments can be made to predict flowers with an outer whorl of leaves and an indeterminate number of whorls of staminoid petals for sup ap2 ag triple mutants (Fig. 7).

In contrast, an epistatic relationship is observed between the sup-1 and pi-1 mutations, with pi-1 being epistatic to sup-1; sup-1 pi-1 flowers are morphologically indistinguishable from $p i-l$ flowers. This is the predicted result if SUP acts as an upstream negative regulator of $P I$.

According to the arguments presented above, ap3 mutations should also be epistatic to sup mutations. This is observed with the strong ap3-3 allele; sup-2 ap33 flowers are indistinguishable from ap3-3 flowers $(\mathrm{H}$. Sakai and E. Meyerowitz, unpublished). However, this is not the case for all ap 3 alleles, such as the weaker $a p 3$ $I$ allele. In sup- $I$ ap 3-I flowers the sup- $I$ mutation has a phenotypic effect in the third whorl in the ap3-1 


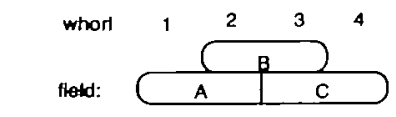

wild-type

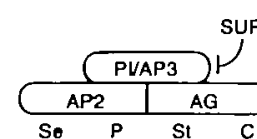

ag sup

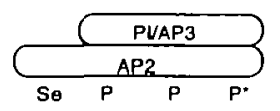

$\operatorname{sep}$

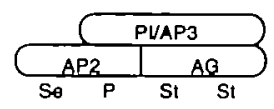

ap3ipl sup

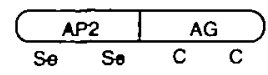

ap2

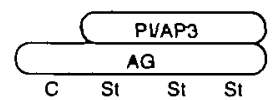

ap2 ag sup

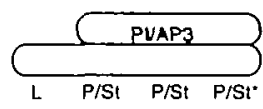

Fig. 7. A schematic representation of the model depicting how SUP could regulate the activity of AP3 and PI in the fourth whorl of the flower.. A section through one-half of a floral primordium is represented as a set of boxes, with the regions representing each whorl shown at the top of each column. Each box represents a single field (defined in Bowman et al., 1991b); these are also shown at the top of the first column. The combination of floral homeotic gene products present in each whorl is proposed to specify the fate of the organ primordia of that whorl. For example, sepals are specified if only AP2 is present, petals if AP3 and PI are present in addition to AP2, carpels are specified if only AG is present, and stamens if AP3 and PI are present in addition to AG. AP2 and AG antagonistically regulate each other such that in ap 2 mutants AG is present in all four whorls (Drews et al., 1991) and, conversely, we predict that in ag mutants AP2 is present in all four whorls. In sup flowers field B, the domain of AP3 and PI activity, expands to include the fourth whorl. The genotype under consideration is listed at the left with the predicted distribution of gene products present in each genotype indicated by uppercase letters within the boxes. The predicted phenotype of the organs in each whorl is shown under the diagrams. $\mathrm{Se}=$ sepal, $\mathrm{P}=$ petal, $\mathrm{St}=$ stamen, $\mathrm{C}=$ carpel. $\mathrm{P} / \mathrm{St}=$ petaloid stamen, an organ, present in sup ap2 ag flowers, with characteristics of both petals and stamens. $\mathrm{L}=$ leaf or carpelloid leaf, either can be found in the positions indicated depending upon the allele of $a p 2$ present. The ${ }^{*}$ is a reminder that in each genotype containing $a g$, there are several whorls of organs interior to the fourth whorl. Details of the model are in the Discussion. Note that this is a simplification, since some carpelloid organs may develop in sup flowers and this model does not address the issue of floral meristem determinacy.

background, a condition not observed in sup-1 single mutants. Specifically, the third whorl organs of these double mutants are more carpelloid and are more often fused together and to the organs deriving from the fourth whorl than is observed in ap3-1 singly mutant flowers (Fig. 2). The sup-1 ap3-1 double mutant resembles the stronger and probably null ap 3 phenotype seen in ap3-3 flowers (Jack et al., 1992). The ap3-1 mutation appears to be a partial loss-of-function allele
(Bowman et al., 1989; Jack et al., 1992). Thus, it seems that the ap3-1 gene product is somehow additionally destabilized or deactivated in the sup-1 background, even more so than it is at high temperature in an otherwise wild-type background. The interaction between ap3-1 and sup-1 is not allele-specific, since similar interactions are observed in sup-2 ap3-1 (H. Sakai and E. Meyerowitz, unpublished) and sup -3 pi-3 flowers $(\mathrm{H}$. Sakai and E. Meyerowitz, unpublished; the pi-3 phenotype is similar to the ap3-1 phenotype, Bowman et al., 1991b). The basis for these unexpected interactions in the third whorl is unknown. However, epistasis in the fourth whorl confirms the basic conclusion that the sup phenotype is mediated by ectopic $A P 3$ expression.

In summary, the phenotypes of all the doubly and triply mutant flowers described here and the expression pattern of AP3 RNA in sup flowers support the hypothesis that SUPERMAN acts on organ identity by repressing AP3, and perhaps PI, activity in the fourth whorl. Consequently, sup mutants have both $\mathrm{AG}$ and AP3/PI activity in the region that in wild type is the fourth whorl, resulting in the differentiation of the fourth whorl primordia as stamens according to the proposed organ identity specification model outlined in Fig. 7 (Bowman et al., 1991b). The repression of AP3/PI activity by SUP need not be direct.

Mutations in either $A P 3$ or $P I$ result in a similar phenotype, and ap3 pi double mutants have a phenotype similar to that of the single mutants (Bowman et al., 1989). In pi-1 flowers, AP3 RNA is expressed in the normal spatial pattern early in flower development, but petals and stamens fail to form (Jack et al., 1992). These data suggest that the expression of $A P 3$ alone is insufficient to direct the proper development of petals and stamens and that both $A P 3$ and $P I$ activities are necessary for petal and stamen development. Therefore, $S U P$ need only repress the activity of one of the two genes, $A P 3$ or $P I$, in the fourth whorl to allow carpel development. In wild-type flowers, $A P 3 \mathrm{RNA}$ is restricted to whorls two and three (Jack et al., 1992). We have shown that the initial expression pattern of AP3 expands into the fourth whorl in sup flowers indicating that SUP represses AP3 activity in the fourth whorl at the level of RNA.

\section{The center of the flower}

Although the initial inner boundary of $A P 3$ expression is shifted towards the center of the flower in sup mutants, there remains a region of cells at the center of the floral meristem that does not accumulate a detectable level of $A P 3$ RNA. In the second and third whorl primordia of both wild-type and sup flowers the appearance of $A P 3$ RNA precedes the morphological development of those organ primordia (Fig. 5A-B,EF). In sup flowers, the floral meristem, after the second and third whorl primordia have formed, behaves morphologically similarly to the wild-type floral meristem, after the first and second whorl primordia have formed; organ primordia are initiated on its flank, each of which differentiates into a stamen. In these organ 
primordia, $A P 3$ expression is similar to that observed in the third whorl in wild-type flowers, commencing slightly prior to the formation of the organ primordia, while the central portion of the floral meristem continues to exhibit no detectable AP3 RNA (Fig. 5G$\mathrm{H})$. These observations suggest that $A P 3$ expression may be initiated sequentially in the marginal regions of the floral meristem, as the inner whorls of organ primordia are produced from these regions. In this model, cells of the central region would continue to divide and differentiate, producing additional rings of organ primordia that behave as third whorl organ primordia of wild-type flowers. In other words, the floral meristem may be transiently stuck in developmental time, forming extra rings of organs that resemble the third whorl of wild-type flowers. Alternatively, the central region of the floral meristem interior to the third whorl could be destined to give rise only to the carpelloid organs of sup flowers (see below), while the outer region (where AP3 RNA is present from the start) of the meristem could give rise to the extra stamens. The patterns of cell division in the early development of wild-type and sup flowers will have to be followed in detail to distinguish between these hypotheses.

It is not clear why the central region of the floral meristem fails to express AP3 in sup flowers. It is not simply the case that these cells remain undifferentiated with respect to floral homeotic gene expression since $A G$ RNA is detected in these cells. Although each of the four known mutant sup alleles cause similar flower pattern defects, it is not known whether they are null alleles. Thus, one possible explanation is that sup-1 may be a partial loss of function, and the sup-1 product may retain some activity, resulting in the observed $A P 3$ expression pattern. Alternatively, the central cells could have a different repressor of $A P 3$ activity, or could have never expressed the initial (unknown) activator of $A P 3$.

\section{Carpel-stamen mosaic organs}

The absence of $A P 3$ expression at the center of the flower can explain the development of carpelloid organs at the center of sup flowers. Organ primordia derived entirely from the non- $A P 3$-expressing part of the floral meristem would be expected to differentiate into carpels. Often, however, the tissue present in the central region of sup flowers is a fusion of staminoid and carpelloid tissues. It may be that there are not enough cells in the center of sup flowers that do not express $A P 3$ to give rise to a complete carpel primordium, and thus, the organ primordia from which these mosaic organs are derived straddle the inner boundary of $A P 3$ expression. Consequently, different regions of individual organ primordia would have different fates, due to the different combinations of floral homeotic genes expressed: $A G$ plus $A P 3 / P I$, or $A G$ alone. The result would be the development of mosaic organs. Likewise, in sup-1 ag-1 flowers, whose floral meristems also display a central region lacking detectable $A P 3$ expression, organs with some sepaloid-characteristics are observed in the inner whorls. Perhaps these organs are derived from primordia that develop near the inner boundary of $A P 3$ expression, where AP3 activity might be variable.

\section{The fourth whorl of superman agamous flowers}

The numbers and positions of the sepaloid organs in the fourth whorl of ag flowers support the interpretation that these organs constitute the first whorl of an internal flower, rather than a fourth whorl (Bowman et al., 1991b). In addition, in ag-2 flowers that are in a wildtype ERECTA background, pedicel elongation is observed between successive internal flowers (after every three whorls), suggesting that the fourth whorl in these flowers is developing as the first whorl of an internal flower. Thus, the structure of ag flowers is a reiterated pattern of whorls, (first whorl, second whorl, third whorl $)_{n}$, with no fourth whorl organs ever forming. In contrast, in sup-1 ag-2 flowers in a wild-type ERECTA background, there is no significant elongation of the pedicel between any of the inner whorls. This would suggest that in sup ag flowers, all organs interior to the second whorl iterate only one developmental program, with no internal flowers forming. Thus, once again the floral meristem appears to be transiently stuck in developmental time producing an indeterminate number of third whorl organs.

\section{Control of whorl identity and determinacy of the floral meristem}

More than twenty stamens can develop interior to the second whorl in superman-1 flowers, suggesting that the SUPERMAN product may have a role in regulating floral meristem determinacy in addition to defining boundaries of organ identity. It is not simply the case that the fourth whorl organ primordia, which number two or four depending on interpretation (Merxmüller and Leins, 1967; Eigner, 1973), develop into stamens. The phyllotaxy of the extra primordia in superman-1 flowers is whorled, with, in the most extreme cases, four to five distinct rings of organs developing from those cells that would normally develop into the gynoecium. This reduction in determinacy is not observed in sup-1 ap3-1 or sup-1 pi-1 flowers, indicating that the effect is mediated by AP3/PI activity. Further evidence for AP3/PI activity influencing floral meristem determinacy comes from $A P 3$ expression patterns in floral mutants. Ectopic $A P 3$ expression in the fourth and inner whorls of sup flowers is correlated with supernumerary organs and a partial loss of floral meristem determinacy, while a reduction of $A P 3$ expression in the second and third whorls of ap 2 flowers (mediated by ectopic $A G$ expression) or in pi-1 flowers is correlated with a reduction in the number of floral organs (Jack et al., 1992). This suggests that AP3/PI activity promotes proliferation of the floral meristem.

This points out an additional way of looking at the sup mutants. We have said that the wild-type activity of $S U P$ is to prevent $A P 3$ expression in the fourth whorl of developing flowers, and as a consequence, the organs of the-fourth -whorl are converted to stamens: But the 
number and position of the organs internal to the third whorl stamens in sup flowers indicate that they are third whorl organs, not converted fourth whorl organs. This suggests that $S U P$ acts not only to repress $A P 3$ expression in the fourth whorl, but is at the same time preventing the conversion of the cells that in wild type constitute the fourth whorl to a series of third whorls (as defined by the number and position of organs). In the absence of wild-type $S U P$, this conversion occurs, but is dependent upon the wild-type activity of $A P 3$, since the fourth whorl is present in ap3 sup double mutants. Perhaps the clearest way to express this at present is to consider the sup flower to consist initially of four whorls, as in wild-type, but ectopic expression of $A P 3$ (and perhaps other genes) not only respecifies organ identity in the fourth whorl, but also specifies a number and position of organs equivalent to a wild-type third whorl. In this view, $A P 3$ acts in the fourth whorl as more than an organ identity gene: it is both an organ and a whorl identity gene.

In sup-1 ag-1 flowers, the floral meristem continues to produce organ primordia indeterminately, with the floral meristem becoming enlarged and elongated, to over $100 \mu \mathrm{m}$ in length, and producing organ primordia along its entire margin. This type of fasciated floral meristem has been observed in ag-1 clavata2 flowers (John Alvarez and David Smyth, personal communication). The clavata (clv1, clv2, and clv3) mutations cause the floral meristem to be enlarged relative to wild type with the result that clavata flowers have a fourcarpelled gynoecium and occasionally extra organs in the other whorls as well. The clavata mutations affect vegetative and inflorescence as well as floral meristems (J. Bowman, unpublished), while superman and agamous mutations specifically affect the floral meristems. Both superman and clavata2 mutations interact synergistically with ag mutations to result in uncontrolled meristematic growth. This suggests that AG and SUP (via AP3/PI) function in concert with other gene products, such as the $C L V$ gene products, involved in regulating meristematic cell division throughout the plant, to control whorl identity and determinacy of the floral meristem.

\section{Evolutionary considerations}

It has recently been shown that the $A P E T A L A 3$ gene of Arabidopsis and the DEFICIENS gene of Antirrhinum (Sommer et al., 1990) are homologues both at the level of mutant phenotype and DNA sequence (Jack et al., 1992). This suggests that the mechanisms utilized in floral pattern formation in Arabidopsis may be widespread among dicotyledonous plants. It is tempting to speculate that mutations in other species that result in phenotypes similar to superman, such as R-n57 described in Petunia (Turlier et al., 1991), may also be in homologous genes.

In contrast to the floral homeotic genes, whose activity specifies the identity of the floral organs, SUPERMAN belongs to another class of genes regulating flower pattern. These genes, for which we propose the term 'cadastral' genes, are involved in setting the boundaries of floral homeotic gene activities during floral development. Other as yet unidentified genes may be involved in similar roles in defining the initial expression patterns of the homeotic genes, such as the outer boundary of AP3/PI activity, while the homeotic genes, $A G A M O U S$ and $A P E T A L A 2$, appear to serve cadastral roles in determining each other's pattern of expression, in addition to their organ specification activities. Modifications of the spatial and temporal expression of the cadastral genes in different species could in part be responsible for the enormous variation observed in the structure of angiosperm flowers.

We thank our colleagues Laura Brockman, Caren Chang, Gary Drews, Shing Kwok, and Mark Running for insightful discussion and critical review. We also thank Elizabeth Schultz, George Haughn, Russell Malmberg, John Alvarez, and David Smyth for providing genetic material, and Pat Koen of the Electron Microscope Facility at Caltech for technical advice. This study was assisted by National Science Foundation grant DCB-8703439 to E. M. M. J. L. B. was partially supported by training grant 5T32-GM07616 of the National Institutes of Health, H. S. was supported by a long. term fellowship from the Human Frontier Science Program, T. J. was supported by NIH post-doctoral grant GM-1366702, D. W. was an EMBO long-term fellow, U. M. was supported by the DFG (Leibnizprogramm to Herbert Jäckle, grant Ju 179/2-1 to Gerd Jürgens).

\section{References}

Bowman, J. L., Drews, G. N. and Meyerowitz, E. M. (1991a). Expression of the Arabidopsis homeotic gene AGAMOUS is restricted to specific cell types late in flower development. The Plant Cell 3, 749-758

Bowman, J. L. and Meyerowitz, E. M. (1991). Genetic control of pattern formation during flower development in Arabidopsis thaliana. In Molecular Biology of Plant Development, Symposium of the Society of Experimental Biology. XLV. (G.I. Jenkins and W. Schuch, eds.) (Cambridge: The Company of Biologists, Ltd.), 89 115.

Bowman, J. L., Smyth, D. R., and Meyerowitz, E. M. (1989). Genes directing flower development in Arabidopsis. Plant Cell 1, 37-52.

Bowman, J. L., Smyth, D. R. and Meyerowitz, E. M. (1991b). Genetic interactions among floral homeotic genes of Arabidopsis. Development 112, 1-20.

Bowman, J. L., Yanofsky, M. F. and Meyerowitz, E. M. (1988) Arabidopsis thallana: A review. In Oxford Surveys of Plan Molecular and Cell Biology, Vol. 5. (B. J. Miflin, ed.) (Oxford: Oxford University Press), pp. 57-87.

Chang, C., Bowman, J. L., DeJohn, A. W., Lander, E. S. and Meyerowitz, E. M. (1988). Restriction fragment polymorphism linkage map for Arabidopsis thaliana. Proc. Natl. Acad. Sci. USA $85,6856-6890$.

Cox, K. H. and Goldberg, R. B. (1988). Analysis of plant gene expression. In Plant Molecular Biology: A Practical Approach. (C. H. Shaw, ed.) (Oxford: IRL Press), pp. 1-34.

Drews, G. N., Bowman, J. L. and Meyerowitz, E. M. (1991). Negative Regulation of the Arabidopsis Homeotic Gene AGAMOUS by the APETALA2 Product. Cell 65, 991-1002.

Eigner, J. (1973). Zur Stempel- und Fruchtentwicklung ausgewahlter Brassicaceae (=Cruciferae) unter neueren Gesichtspunkten der Blutenmorphologie und der Systematik. Beitr. Biol. Pflanzen 49 $359-427$.

Haughn, G. W. and Somerville, C. R. (1988). Genetic control of morphogenesis in Arabidopsis. Dev. Genet. 9, 73-89.

Hill, J. P. and Lord, E. M. (1989). Floral development in Arabidopsis thaliana: a comparison of the wild type and the homeotic pistillato mutant. Can. J. Bot. 67, 2922-2936. 
Irish, V. F. and Sussex, I. M. (1990). Function of the apetala-1 gene during Arabidopsis floral development. The Plant Cell 2, 741-753.

Jack, T., Brockman, L. L. and Meyerowitz, E. M. (1992). The homeotic gene APETALA3 of Arabidopsis thaluana encodes a MADS box and is expressed in petals and stamens. Cell, in press.

Komaki, M. K., Okada, K., Nishino, E. and Shimura, Y. (1988). Isolation and characterization of novel mutants of Arabidopsis thaliana defective in flower development. Development 104, 195 203.

Kunst, L., Klenz, J. E., Martinez-Zapater, J. and Haughn, G. W. (1989). AP2 gene determines the identity of perianth organs in flowers of Arabidopsis thaliana. Plant Cell 1, 1195-1208.

Lander, E. S., Green, P., Abrahamson, J., Bartow, A., Daly, M., Lincoln, S. E. and Newberg, L. (1987). MAPMAKER: An interactive computer package for constructing primary genetic linkage maps of experimental and natural populations. Genomics $1,174-181$.

Ma, H., Yanofsky, M. F. and Meyerowitz, E. M. (1991). AGLI $A G L 6$, an Arabidopsis gene family with similarity to floral homeotic and transcription factor genes. Genes Dev. 5, 484-495.

Merxmüller, H. and Leins, P. (1967). Die Verwandtschaftsbeziehungen der Kreuzblutler und Mohngewächse. Bot. Jb. 86, 113-129.

Meyerowitz, E. M., Bowman, J. L., Brockman, L. L., Drews, G. N., Jack, T., Skeburth, L. E. and Wefgel, D. (1991). A genetic and molecular model for flower development in Arabidopsis thaliana. Development 1991 Supplement 1, 157-167.

Meyerowitz. E. M., Smyth. D. R. and Bowman, J. L. (1989) Abnormal flowers and pattern formation in floral development. Development 106, 209-217.

Mäller, A. (1961). Zur Charakterisierung der Bluten und Infloreszenzen von Arabidopsis thaliana (L.) Heynh. Kulturpflanze 9, 364-393.

Norman, C., Runswick, M., Pollock, R. and Trelsman, R. (1988). Isolation and properties of cDNA clones encoding SRF, a transcription factor that binds to the $\mathrm{c}$-fos serum response element. Cell 55, 989-1003.

Passmore, S., Maine, G. T., Elble, R., Christ, C. and Tye, B. K. (1988). A Saccharomyces cerevisiae protein involved in plasmid maintainance is necessary for mating of MATa cells. J. Mol. Biol. 204, 593-606.

Pruitt, R. E., Chang, C., Pang, P. P.-Y. and Meyerowitz, E. M. (1987). Molecular genetics and development of Arabidopsis. In Genetic Regulation of Development, 45th Symp. Soc. Dev. Biol. (W. Loomis, ed.) (New York: Liss), pp. 327-338.
Scholtz, E. and Haughn, G. (1990). The role of FLO10 in specifying the identity of reproductive organs in flowers of Arabidopsis thaliana. Abst. Fourth International Conference On Arabidopsis Research, Vienna, p. 126.

Schultz, E. and Haughn, G. (1991). LEAFY, a homeotic gene that regulates inflorescence development in Arabidopsis. Plant Cell 3, $771-781$.

Schwarz-Sommer, Z., Huljser, P., Nacken, W., Saedler, H. and Sommer, H. (1990). Genetic control of flower development by homeotic genes in Antirrhinum majus. Science 250, 931-936.

Smyth, D. R., Bowman, J. L. and Meyerowitz, E. M. (1990). Early flower development in Arabidopsis. Plant Cell 2, 755-767.

Sommer, H., Beltran, J. P., Huijser, P., Pape, H., Lönnig, W.-E., Saedler, H. and Schwarz-Sommer, Z. (1990). Deficiens, a homeotic gene involved in the control of flower morphogenesis in Antirrhinum majus: the protein shows homology to transcription factors. $E M B O$ J. 9, 605-613.

Turlier, M.-F., Alabouvette, J. and Doulain-Douvler, D. (1991). La morphogenèse florale chez le pétunia. III. Deviations dans le programme organogène chez un mutant femelle stérile. Can. J. Bot. 69, 866-872.

Yanofsky, M. F., Ma, H., Bowman, J. L., Drews, G. N., Feldmann, K. A. and Meyerowitz, E. M. (1990). The protein encoded by the Arabidopsis homeotic gene agamous resembles transcription factors. Nature 346, 35-39.

(Accepted 27 November 1991)

\section{Note added in proof}

While this paper was in press, an additional paper describing effects of mutation in the SUPERMAN locus (under the name FLO1O) has been published (Schultz, E., Pickett, F. B. and Haughn, G. W., 1991, The FLO10 gene product regulates the expression domain of homeotic genes AP3 and PI in Arabidopsis flowers, Plant Cell 3, 1221-1227). The correspondence of allelic designations between those in this paper (and in Bowman and Meyerowitz, 1991, and Meyerowitz et al., 1991 ) and the three alleles mentioned by Schultz et al. is: sup $-1=$ flo10-2; sup-2 = flo10-1; and sup-3 = flo $10-3$. 
